\title{
Experimental identification of dynamic coefficients of lightly loaded tilting-pad bearings under several lubrication regimes
}

Salazar, Jorge G.; Santos, IImar F.

Published in:

Institution of Mechanical Engineers. Proceedings. Part J: Journal of Engineering Tribology

Link to article, DOI:

$10.1177 / 1350650116635926$

Publication date:

2016

Document Version

Peer reviewed version

Link back to DTU Orbit

Citation (APA):

Salazar, J. G., \& Santos, I. F. (2016). Experimental identification of dynamic coefficients of lightly loaded tiltingpad bearings under several lubrication regimes. Institution of Mechanical Engineers. Proceedings. Part J: Journal of Engineering Tribology, 230(12), 1423-1438. https://doi.org/10.1177/1350650116635926

\section{General rights}

Copyright and moral rights for the publications made accessible in the public portal are retained by the authors and/or other copyright owners and it is a condition of accessing publications that users recognise and abide by the legal requirements associated with these rights.

- Users may download and print one copy of any publication from the public portal for the purpose of private study or research.

- You may not further distribute the material or use it for any profit-making activity or commercial gain

- You may freely distribute the URL identifying the publication in the public portal 


\title{
Experimental identification of dynamic coefficients of lightly-loaded tilting-pad bearings under several lubrication regimes
}

\author{
Jorge G. Salazar ${ }^{1,2}$ and IImar F. Santos ${ }^{1}$
}

\begin{abstract}
This paper presents the identified dynamic coefficients of a lightly-loaded actively-lubricated bearing under three lubrication regimes: passive, hybrid and feedback-controlled. The goal is to experimentally demonstrate the feasibility of modifying the bearing dynamic properties via active lubrication. Dominated by the latest two regimes, the bearing properties become adjustable or controllable due to the injection of either a constant or variable pressurized oil flow. Such a flow is regulated by a hydraulic control system composed of a) a high pressure oil supply unit, b) servovalves, c) radial injection nozzles, d) displacement sensors and e) well-tuned digital controllers. A scaled-down industrial rotor featuring active lubrication, composed of a flexible rotor supported by a four-rocker load-between-pads tilting pad bearing under light load condition, is used for this objective. The experimental identification is performed by means of measured frequency response functions and a rotor finite element model. Predicted coefficients are also provided for benchmarking. Comparing results between the different regimes, presented along with their expanded uncertainty, provides the experimental evidence of the bearing properties modification via active lubrication.
\end{abstract}

\section{Keywords}

Tilting-pad journal bearings, lightly-loaded bearing, active lubrication, dynamic force coefficients, frequency-domain identification

\section{Introduction}

Tilting-pad journal bearings (TPJB) have experienced widespread usage to the point of becoming a standard machine element when designing high speed turbomachinery. This is due to their distinguishing stability characteristics among fluid film bearings ${ }^{1}$, which strongly influence the dynamic characteristics of the entire rotor-bearing system. Such characteristics are predefined at an early design stage when selecting machines for specific process lines. However, increasing demands of plant production still requires faster machines with enhanced load carrying capacity and dynamic stability able to adapt themselves to the new requirements. One way to fulfill these requirements is by modifying the bearing properties according to such demands. Nevertheless, the dynamic properties of a standard TPJB are completely determined by its Sommerfeld number ${ }^{2}$ and there is no way of significantly "on-line" changing such properties. In order to provide "in-situ", "on-line" and "on-demand" capabilities of adaptation, standard TPJBs have been re-designed and transformed into a mechatronic machine element.

Santos $^{3}$ proposed two different design solutions for TPJBs with controllable characteristics based on hydraulic actuators: 1) the hydraulic chamber system and 2) the hydraulic radial oil injection system. The present work is focused on the second design solution also known as actively-lubricated bearing ${ }^{4}$ (ALB). This system injects pressurized oil into the bearing clearance through radial nozzles usually placed at the midspan of the pad surface. Servovalves, commanded by well-defined control laws, control the pressurized oil flow injection, resulting in a modification of the oil film pressure field and thereby of the "controllable forces" exerted on the rotor. Most of the early theoretical studies on ALBs considered isoviscous hydrodynamic models, focusing on the development of control strategies for rigid as well as flexible rotor applications ${ }^{5-9}$. Multibody dynamics and finite element methods are often used to describe the behaviour of rigid and flexible rotating elements, i.e. discs and shaft. Their dynamics are linked to the bearing dynamics through force coefficients of stiffness and damping. In the case of ALBs, the dynamics of hydraulic components and of the feedback control system are additionally included in the modelling. In this multiphysics modelling approach, experimental identification of bearing force coefficients is key to ensuring model accuracy.

The bearing coefficients are experimentally identified in terms of the journal degrees-of-freedom (DOFs) since they are of crucial importance and normally the only ones easily accessible via eddy-current displacement sensors. Such DOFs are normally called "master" DOFs. DOFs such as the pad tilting ${ }^{10}$, pad bending ${ }^{11}$ and pad pivot flexibility ${ }^{10 ; 12-16}$ are not directly measured, but strongly influence the dynamic

\footnotetext{
${ }^{1}$ Department of Mechanical Engineering, Technical University of Denmark, Kgs. Lyngby, Denmark

${ }^{2}$ Department of Mechanical Engineering, University of La Frontera, Temuco, Chile
}

\section{Corresponding author:}

Ilmar F. Santos, Department of Mechanical Engineering, Technical University of Denmark, Nils Koppels Allé, Building 404, 2800 Kgs. Lyngby, Denmark.

Email: ifs@mek.dtu.dk 
behaviour of such force coefficients, leading to a frequency dependency. Furthermore, in the case of ALBs, the DOFs related to servovalve dynamics, pressure-flow relationship and feedback control make the frequency dependency of such force coefficients even stronger. The DOFs different from those of the journal are normally called "slaves" DOFs. To make the theoretical force coefficients comparable to those experimentally obtained, a dynamic condensation of the "slaves" DOFs is necessary.

By using the identification methods based on the frequency domain, the bearing dynamic characteristics - represented by complex impedance functions - are determined in a broad frequency range aided by multifrequency excitations. One of the most used methods is the KCM model ${ }^{17-20}$ introduced for hydrostatic bearings by Rouvas and Childs ${ }^{21}$ and mostly applied to "floating bearingfixed shaft" setups after Glienicke ${ }^{22}$. The KCM approach experimentally addresses the frequency dependency by introducing a set of mass coefficients which account for bearing stiffening or softening. However, its application is meant for rigid rotors. To cope with flexible rotors, like the one in this work, Arumugam et al. ${ }^{23}$ and Wang and Maslen ${ }^{24}$ proposed approaches based on "fixed bearing-free shaft" configurations. The limitation of such approaches arises when dealing with systems with a large number of DOFs. This limitation can be more easily overcome by introducing selector matrices ${ }^{24}$, which allow for the selection of a few DOFs related to excitation and measurement points.

Two main publications related to the identification of dynamic coefficients of controllable fluid film bearings are found in the literature. In Santos ${ }^{13}$ a pair of tilting-pads controlled by hydraulic chambers are investigated and the frequency dependency of stiffness and damping coefficients is theoretically as well as experimentally studied. Therein, a simple hydrodynamic (isothermal) model with rigid pads supported on flexible membranes is explored. Conversely, in Cerda and Santos ${ }^{25}$, the stiffness and damping coefficients for a single tilting-pad under several lubrication regimes are theoretically and experimentally researched. Therein, a complex elastothermohydrodynamic (ETHD) model for a single-pad ALB is used. The experimental work is carried out using a simple test rig, but with pads fully instrumented.

In this framework the main goals of this paper are: a) to experimentally demonstrate the feasibility of modifying the dynamic force coefficients of full ALB composed of four pads controlled pairwise by two servovalves. Lightly-loaded conditions are used with the aim of resembling certain radial compressor configurations ${ }^{5}$ and some applications to vertical turbomachinery ${ }^{26}$ in which TPJBs are prone to instabilities due to, among others, the lack of damping. Such instabilities, led by low static loads, have been profusely reported for instance by Olsson ${ }^{27}$, White and Chan ${ }^{28}$, Flack and Zuck ${ }^{29}$ and Lie et al. ${ }^{30}$ among others.

b) to build an experimental database for validation of the ETHD model applied to ALBs under different operation conditions, which will be useful and available for other authors interested in the dynamic behaviour of TPJB under several lubrication regimes and the frequency dependency of its force coefficients. Due to the frequency dependence nature of the bearing force coefficients, the experimental identification procedure is carried out in the frequency domain aided by the approach presented by Wang and Maslen $^{24}$, taking advantage of the finite element model to include the shaft flexibility and to compute the expanded uncertainty as proposed by Moffat ${ }^{31}$.

\section{The Flexible Rotor - ALB Test-Rig}

The test rig is depicted in Figure 1. It comprises an approx. $50 \mathrm{~kg}$ and $1150 \mathrm{~mm}$ long shaft (2) supported by an ALB (3) and rigidly supported by a ball bearing (6) at its driven end. It is flexibly driven by a layshaft which in turn is belt-driven by a $4 \mathrm{hp} \mathrm{AC} \mathrm{motor} 7$ provided with a frequency converter to run up to $7000 \mathrm{rpm}$. An active magnetic bearing (5) is currently mounted between bearings to exert vertical loads up to $1900 \mathrm{~N}^{32}$. An excitation bearing (1) is placed at the free end to carry out model parameter identification by means of an electromagnetic shaker. The ALB is a tiltingpad journal bearing with 4 bronze pads in a load-betweenpads (LBP) configuration. The pads are rocker-pivoted in the circumferential middle of the pad, i.e. with an offset of 0.5 . The controllable or active feature of the bearing is developed by a hydraulic radial oil injection system as proposed by Santos ${ }^{4}$. This injection system adds a hydrostatic pressure to the hydrodynamic pressure distribution by injecting pressurized oil between the journal and pad clearance through a nozzle placed in the middle of the pad surface. The pressurized oil flow is controlled by two high frequency response servovalves installed orthogonally at $45^{\circ}$, aligned with the " $1-2$ " reference frame, each one coupled to a pairwise of counter pads. The lubricant is supplied by a low pressure (max. 2 bar) and high pressure (max. 100 bar) pumping units for the passive and active lubrication cases, respectively. Figure 1 also depicts a scheme of the radial oil injection system overlapped by a 3D drawing of the ALB. Eddy-current inductive proximity probes, aligned with the " $x-y$ " reference frame, and used for monitoring and feeding back controllers are also included. Further design parameters can be found in Table 1 .

\section{The Three Lubrication Regimes}

The ALB is capable of operating under three different lubrication regimes, namely:

i) the passive regime which gives the hydrodynamic backup support in terms of the load carrying capacity in case of a hydraulic injection system failure;

ii) the hybrid lubrication regime which is a combination of the passive case with a hydrostatic effect developed by the hydraulic injection system. The larger the pressure in the high pressure unit, the more pronounced the hydrostatic effect obtained. Since the bearing is a four pad arrangement in an LBP configuration and governed by two servovalves shifted $45^{\circ}$, the journal can be moved within the plane “ $x-y$ ". However, since the servovalves' dynamic properties are slightly different, the journal cannot be strictly moved upward or downward without the aid of an I-controller ${ }^{33}$. When the servovalve spool is kept centred there is still some hydrostatic effect detectable as a consequence of leakage flow through servovalve ports. The servovalves used are of 


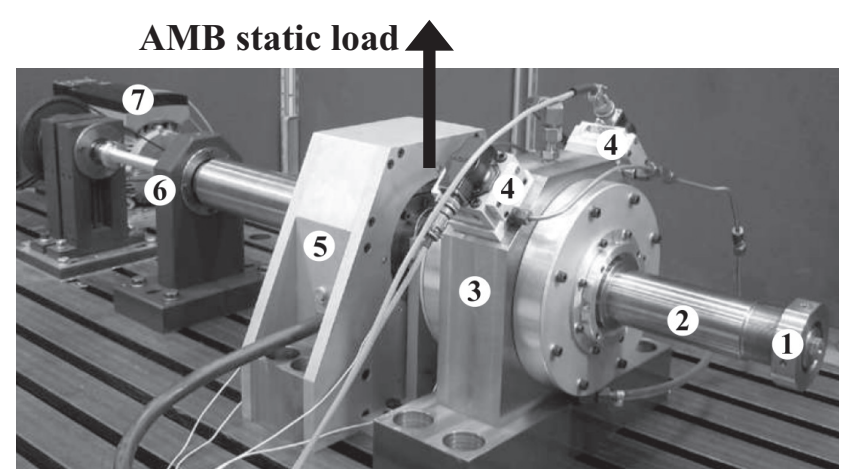

(a)

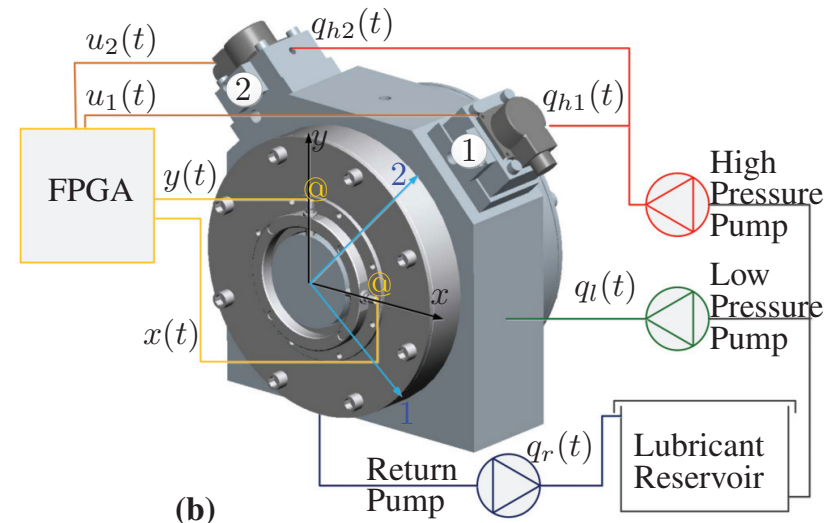

(b)

Figure 1. Flexible rotor - ALB test-rig. (a) picture of the test-rig and its main components: (1) the excitation bearing, (2) the flexible shaft, (3) the actively-lubricated bearing (ALB), (4) servovalves, (5) the active magnetic bearing, (6) the ball bearing, (7) the AC motor with frequency driver. (b) A scheme of the radial oil injection control system overlapped to the ALB with its main parts, the high pressure supply unit, the servovalves (1) and (2), proximity sensors @ and the digital controller (FPGA). Low pressure and return pumping units as well as the fixed orthogonal reference frames " $x-y$ " and " $1-2$ " are also included.

Table 1. Conventional and controllable design parameters of the actively-lubricated bearing (ALB).

\begin{tabular}{llllll}
\hline $\begin{array}{l}\text { Conventional } \\
\text { Design Parameters }\end{array}$ & Value & Units & $\begin{array}{l}\text { Controllable } \\
\text { Design Parameters }\end{array}$ & Value & Units \\
\hline Journal radius $(R)$ & 49.89 & $\mathrm{~mm}$ & Servovalve type & MOOG E760-912 & - \\
Pad inner radius $\left(R_{p}\right)$ & 50 & $\mathrm{~mm}$ & Servovalve configuration & 4 way, spool valve & - \\
Pad aperture angle $\left(\alpha_{p}\right)$ & 69 & $\circ$ & Cut-off frequency $(210$ bar $)$ & 350 & $\mathrm{~Hz}$ \\
Pad width $(L)$ & 100 & $\mathrm{~mm}$ & Damping (210 bar) & 0.7 & - \\
Pad thickness $(t)$ & 14 & $\mathrm{~mm}$ & Control flow $(210 \mathrm{bar})$ & 19.2 & $\mathrm{~L} / \mathrm{min}$ \\
Nominal radial clearance $\left(C_{p}\right)$ & 110 & $\mu \mathrm{m}$ & Cut-off frequency $(100$ bar) & 260 & $\mathrm{~Hz}$ \\
Assembly radial clearance $\left(C_{b}\right)$ & 83 & $\mu \mathrm{m}$ & Injection orifice diameter $\left(d_{0}\right)$ & 3.3 & $\mathrm{~mm}$ \\
Lubrication oil type & ISO VG22 & - & Injection orifice length $\left(L_{0}\right)$ & 21 & $\mathrm{~mm}$ \\
Nominal flow $(2$ bar $)$ & 1.4 & $\mathrm{~L} / \mathrm{min}$ & & & \\
\hline
\end{tabular}

an underlapped ${ }^{*}$ type. This case is referred to throughout the paper as "leakage case". When the lubricant is injected from the two bottom pads, leading to vertical upward lift forces, it is referred to as upward case, see Figure 2(a). When it is injected from the two upper pads, it is referred to as downward case, see Figure 2(b).

iii) the feedback-controlled lubrication regime (active lubrication) in which the hydrostatic effect is dynamically modified by the servovalves and well-tuned digital controllers. Different classical or modern control strategies can be developed aided by model-free ${ }^{35}$ or model-based approaches. For simplicity, the ones utilized in this work are based on a proportional-derivative (PD) controller.

\section{ALB Modelling}

The state-of-the-art regarding ALB modelling requires the inclusion of several effects apart from the well-known hydrodynamic oil film pressure build-up to achieve an acceptable level of accuracy, i.e. thermal effects related to the oil film temperature build-up, heat transfer among fluidfilm, bearing pads and surroundings, flexibility associated with compliant pivot and pads due to the exerted loads. Additionally, for coping with the controllable features, it is necessary to also include servovalve and pipe flow dynamics. An exhaustive revision of all the involved equations can be found in Cerda and Santos ${ }^{25}$, in which the bearing dynamic

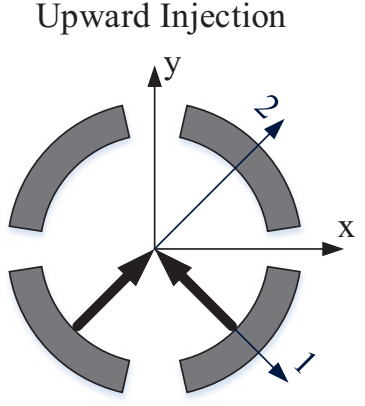

(a)
Downward Injection

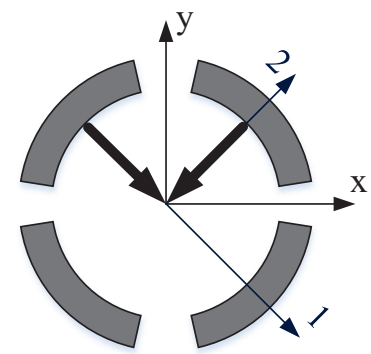

(b)
Figure 2. Injection cases for the Hybrid Lubrication. (a): upward injection through the two bottom pads, resulting in a lifting force. (b): downward injection through the two upper pads, resulting in a loading force.

properties have been validated using a single pad system. Figure 3 shows the predicted coefficients for a full ALB under the operational conditions tested, i.e. $3000 \mathrm{rpm}$, for an almost null applied load (light-load condition) and 80 bar of supply pressure for the injection system. To incorporate the pivot stiffness for calculations, a value of $2 \cdot 10^{7} \mathrm{~N} / \mathrm{m}$

\footnotetext{
*If the width of the land is smaller than the port in the valve sleeve, the valve is said to have an open center or to be underlapped. Quoted from reference ${ }^{34}$.
} 

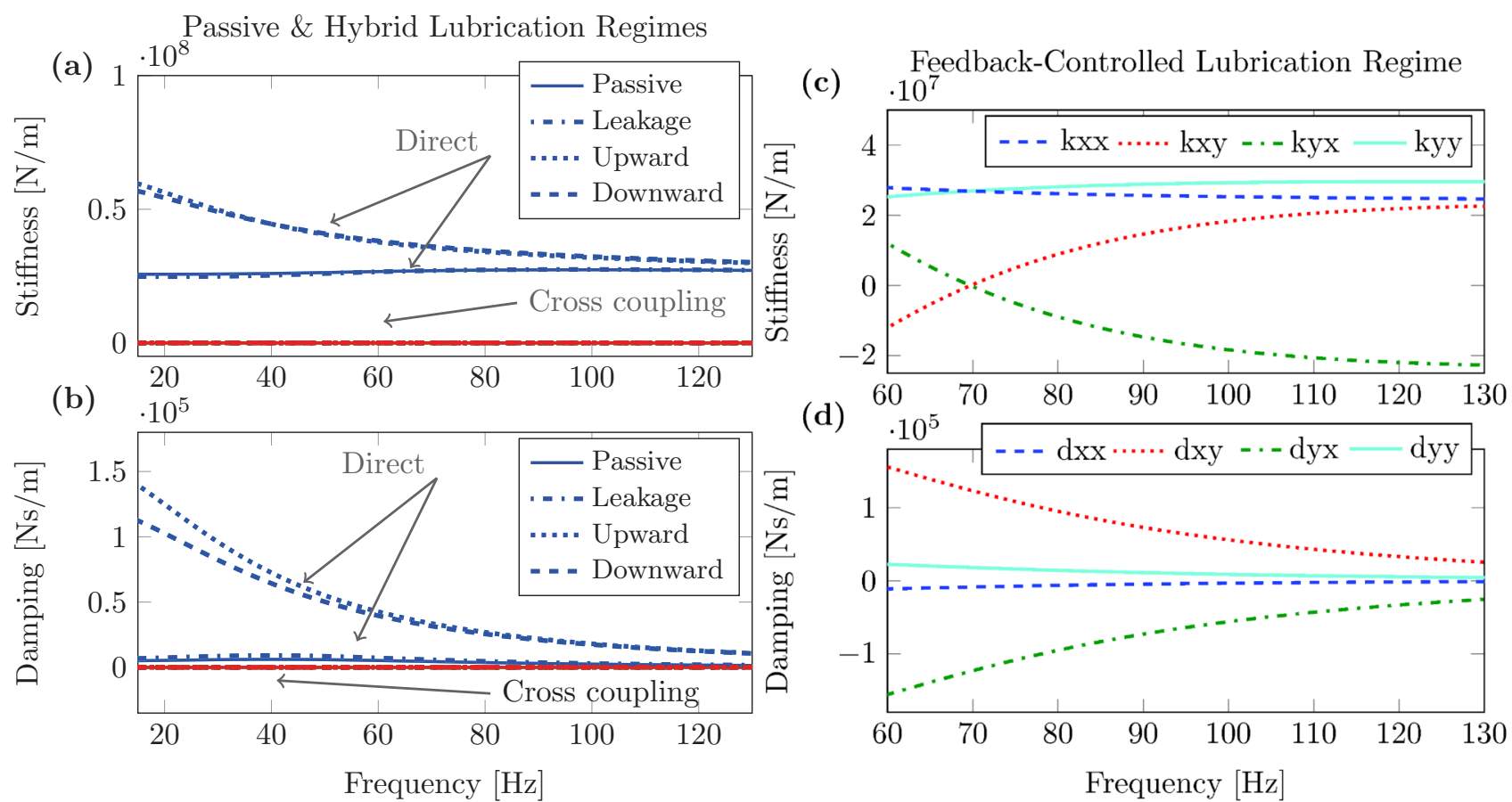

(d)

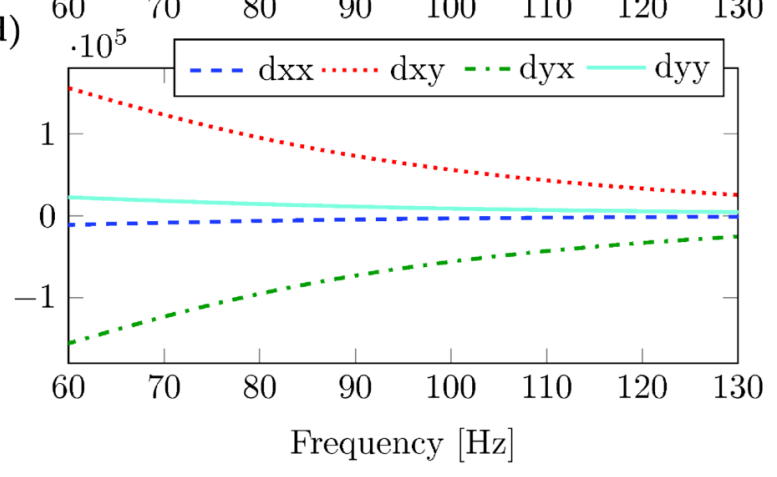

Figure 3. Predicted ALB coefficients by the ETHD approach. (a) and (b): coefficients under passive and hybrid lubrication regimes. Solid line (-): Passive lubrication. Dash-dot line (-.): Hybrid lubrication, leakage case. Dotted line (..): Hybrid lubrication, upward injection. Dashed line (--): Hybrid lubrication, downward injection. (c) and (d): coefficients under feedback-controlled lubrication. PD-controller \#1 of Table 2. Dashed line (--): kxx and dxx. Dotted line (..): kxy and dxy. Dash-dot line (-.): kyx and dyx. Solid line (-): kyy and dyy.

has been considered based on the experimental results obtained in a test rig with a similar pad design ${ }^{25}$. Bearing force coefficients are depicted in Figure 3(a) and (b) for the ALB operating under passive and hybrid lubrication regimes. Due to the bearing symmetry the direct and cross coupling coefficients are respectively equal in both directions, for passive and hybrid cases. Furthermore, the cross coupling coefficients are negligible compared to the direct ones, despite the lightly-loading condition imposed. In the frequency range studied, theory predicts almost constant direct stiffness coefficients in the order of $10^{7} \mathrm{~N} / \mathrm{m}$ and low damping for the passive case (solid line). Almost negligible changes can be observed for the leakage case (dash-dot line). Contrarily, in the upward (dotted line) and downward (dashed line) cases both the stiffness and damping force coefficients significantly increase (about 2.3 times at low frequencies for the stiffness direct coefficients) and slight differences between them can be seen. Such an increase is more significant for the damping coefficients at lower frequencies. The difference between upward and downward cases is also more prominent at lower frequencies.

Results under the feedback-controlled lubrication regime are reported in Figure 3(c) and (d). The control law simulated is reported in Table 2 and it corresponds to the PD-controller \#1. The controller imposes large modification of the cross coupling coefficients (dotted and dash-dot lines) rather than the direct coefficients (solid and dashed lines). It does not necessarily mean an improvement in rotor-bearing system behaviour, it just illustrates the stronger dependency of the bearing force coefficients on the control law implemented.

\section{Identification of ALB Force Coefficients}

A mathematical model capable of representing the relevant rotor-bearing system dynamics must be formulated as a first step. If the shaft is modeled as rigid, then the approach presented by Arumugam et al. ${ }^{23}$ can be used since a reduced number of DOFs are used, leading to the eight linearized oil film bearing coefficients by comparing directly the experimental FRFs against the theoretical ones. Examples of its application to cylindrical and tilting-pad journal bearings can be found in the same reference ${ }^{23}$, and to air foil journal bearings and polymer faced tilting-pad journal bearings in Larsen et al. ${ }^{36}$ and Simmons et al. ${ }^{37}$ respectively.

If shaft flexibility cannot be neglected, the shaft model can be built using the finite element method ${ }^{38}$. Due to the substantially large number of DOFs, it becomes unfeasible to obtain experimental input/output relationships of every single DOF to build an identification procedure. This difficulty can be overcome by applying the method presented by Wang and Maslen ${ }^{24}$, which allows the inclusion of the shaft flexibility and to identify unknown dynamics from a reduced number of input/output relationships. For the sake of completeness the method is summarized in the following section. Nevertheless, the reader is advised to refer to ${ }^{24}$ for a comprehensive presentation of the method.

\section{Finite Element Model of the Shaft and Rotor}

The flexible shaft, depicted in Figure 4, is discretized using 21 finite elements. The model accounts for inertia and flexibility of the shaft. Damping is neglected. The relevant nodes for the identification procedure are highlighted with 


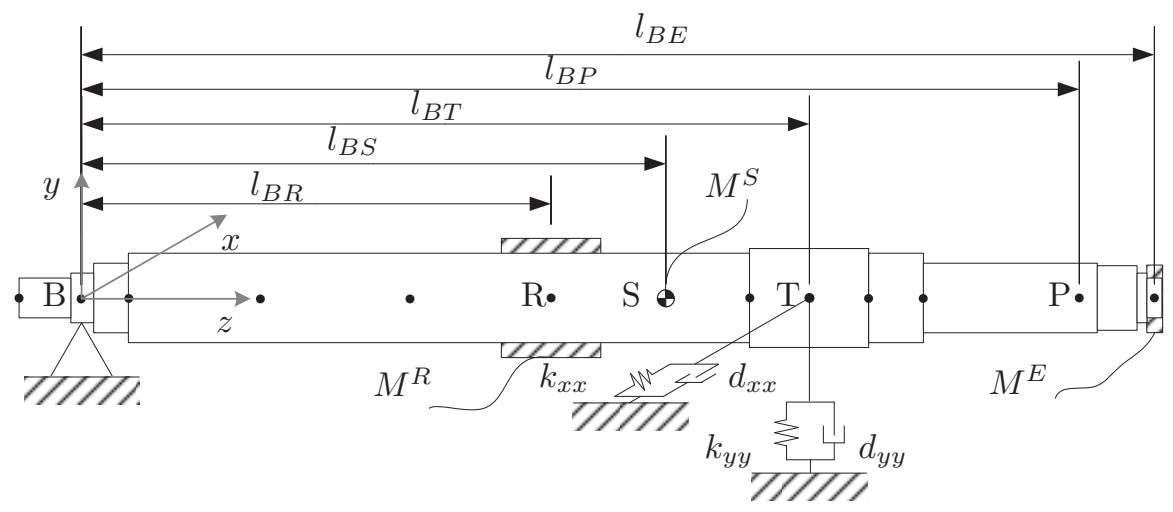

Figure 4. Schematic of the flexible rotor and ALB test rig depicting the finite element discretization. The inertial reference frame$x y z-$ is included. Note that the bearing cross coupling force coefficients have been omitted for simplicity.

black dots, i.e. point (B) for the ball bearing, point (R) for the active magnetic bearing rotor, point $(S)$ for the shaft center of mass, point $(\mathrm{T})$ for the placement of the ALB, point $(\mathrm{P})$ for the placement of the sensor and point $(\mathrm{E})$ for the excitation bearing. Main distances are also depicted and defined as $l_{i j}$ for which the subscripts stand for the distance between points $i$ and $j$. Rigid discs for the active magnetic bearing rotor $M^{R}$ and the excitation bearing $M^{E}$ are placed in their respective nodes, taking into account lumped mass and inertia. The shaft mass $M^{S}$ is distributed along its nodes. The mean values of these parameters are given in Table 3 along with their uncertainty information.

\section{Linking Theoretical and Experimental FRFs}

The procedure is aimed at obtaining the equivalent bearing complex impedance function $\left[\mathbf{H}_{b}(i \omega)\right]$ by means of the measured frequency response functions $\left[\mathbf{F R F}^{*}(i \omega)\right]$ and an equivalent mathematical model of the test setup. The test setup can be dynamically described around an equilibrium position by the well-known equation of motion:

$$
[\mathbf{M}]\{\ddot{\mathbf{q}}\}+\left(\left[\mathbf{D}_{b}\right]-\Omega[\mathbf{G}]\right)\{\dot{\mathbf{q}}\}+\left([\mathbf{K}]+\left[\mathbf{K}_{b}\right]\right)\{\mathbf{q}\}=\{\mathbf{f}\}
$$

where $[\mathbf{M}]$ stands for the generalized inertia matrix, $[\mathbf{G}$ for the gyroscopic matrix, $[\mathbf{K}]$ for the stiffness matrix and $\{\mathbf{f}\}$ and $\{\mathbf{q}\}$ represent the generalized external force and displacement coordinate, respectively. $\Omega$ denotes the angular velocity. The contribution from the ALB in terms of stiffness $\left[\mathbf{K}_{b}(\omega)\right]$ and damping $\left[\mathbf{D}_{b}(\omega)\right]$ is to be determined. Under the assumption of a linear system and considering a harmonic excitation $\{\mathbf{f}(t)\}$ of frequency $\omega$, the generalized coordinate $\{\mathbf{q}(t)\}$ and its time derivatives are dominated by a harmonic response at the same frequency, hence they can be written using complex notation as:

$$
\begin{array}{rlrl}
\{\mathbf{f}(t)\} & =\left\{\mathbf{f}_{\mathbf{0}}\right\} e^{i \omega t} ; & & \dot{\mathbf{q}}(t)\}=i \omega\left\{\mathbf{q}_{\mathbf{0}}\right\} e^{i \omega t} \\
\{\mathbf{q}(t)\} & =\left\{\mathbf{q}_{\mathbf{0}}\right\} e^{i \omega t} ; & \{\ddot{\mathbf{q}}(t)\}=-\omega^{2}\left\{\mathbf{q}_{\mathbf{0}}\right\} e^{i \omega t}
\end{array}
$$

Combining Equation (2) and Equation (1) leads to:

$$
\begin{aligned}
{\left[-\omega^{2}[\mathbf{M}]+i \omega\left(\left[\mathbf{D}_{b}(\omega)\right]-\Omega\right.\right.} & {[\mathbf{G}])+[\mathbf{K}] } \\
+ & {\left.\left[\mathbf{K}_{b}(\omega)\right]\right]^{-1}\left\{\mathbf{f}_{\mathbf{0}}\right\}=\left\{\mathbf{q}_{\mathbf{0}}\right\} } \\
{\left[\left[\mathbf{Z}_{0}\right]+\left[\mathbf{H}_{b}(i \omega)\right]\right]^{-1}=} & {[\mathbf{F R F}(i \omega)] }
\end{aligned}
$$

Equation (3) states the relationship between the system dynamic stiffness matrix $\left[\mathbf{Z}_{0}\right]$ from the finite element model, the unknown bearing impedance function $\left[\mathbf{H}_{b}(i \omega)\right]=$ $\left[\mathbf{K}_{b}(\omega)\right]+i \omega\left[\mathbf{D}_{b}(\omega)\right]$ and the matrix $[\mathbf{F R F}(i \omega)]$ containing the input/output relationships for every degree of freedom in the finite element model. Experimentally, it is not possible to determine every component of this matrix, hence some additional techniques must be applied. By introducing the usage of selector matrices $\left[\mathbf{S}_{i}\right]$ to deal only with several excited/sampled locations, the bearing impedance function $\left[\mathbf{H}_{b}(i \omega)\right]$ can be determined by:

$$
\begin{aligned}
& {\left[\mathbf{H}_{b}(i \omega)\right]=\left[-\left[\mathbf{A}_{\mathbf{T T}}\right]\right.} \\
& \left.\quad+\left[\mathbf{A}_{\mathbf{T E}}\right]\left[\left[\mathbf{A}_{\mathbf{P E}}\right]-\left[\mathbf{F R F} \mathbf{R F}^{*}(i \omega)\right]\right]^{-1}\left[\mathbf{A}_{\mathbf{P T}}\right]\right]^{-1} \\
& {\left[\mathbf{A}_{\mathbf{T E}}\right]=\left[\mathbf{S}_{T}\right]^{T}\left[\mathbf{Z}_{0}\right]^{-1}\left[\mathbf{S}_{E}\right] ;\left[\mathbf{A}_{\mathbf{P E}}\right]=\left[\mathbf{S}_{P}\right]^{T}\left[\mathbf{Z}_{0}\right]^{-1}\left[\mathbf{S}_{E}\right]} \\
& {\left[\mathbf{A}_{\mathbf{P T}}\right]=\left[\mathbf{S}_{P}\right]^{T}\left[\mathbf{Z}_{0}\right]^{-1}\left[\mathbf{S}_{T}\right] ;\left[\mathbf{A}_{\mathbf{T T}}\right]=\left[\mathbf{S}_{T}\right]^{T}\left[\mathbf{Z}_{0}\right]^{-1}\left[\mathbf{S}_{T}\right]}
\end{aligned}
$$

where $\left[\mathbf{S}_{E}\right]$ stands for the selector matrix associated with the excited degrees of freedom (point $\mathrm{E}$ ), $\left[\mathbf{S}_{P}\right]$ stands for the measured degrees of freedom (point $\mathrm{P}$ ) and $\left[\mathbf{S}_{T}\right]$ stands for the bearing degrees of freedom (point $\mathrm{T}$ ). The required experimental data is significantly reduced from $\mathrm{N}$ DOFs to 2 DOFs, since the main requirement to apply the method is that the number of excitations and sensors match the dimension of the un-modeled bearing dynamics. Hence the reduced measured FRFs matrix $\left[\mathbf{F R F}^{*}(i \omega)\right]$ only contains the transfer functions between the excitation point (E) and the response at the measurement point $(\mathrm{P})$. From Equation (4a) the bearing dynamic properties are obtained as the real and imaginary parts of the bearing impedance which reads:

$$
\begin{aligned}
& {\left[\mathbf{K}_{b}\right]=\left[\begin{array}{ll}
\mathrm{K}_{\mathrm{xx}} & \mathrm{K}_{\mathrm{xy}} \\
\mathrm{K}_{\mathrm{yx}} & \mathrm{K}_{\mathrm{yy}}
\end{array}\right]=\Re\left\{\left[\mathbf{H}_{b}(i \omega)\right]\right\}} \\
& {\left[\mathbf{D}_{b}\right]=\left[\begin{array}{ll}
\mathrm{D}_{\mathrm{xx}} & \mathrm{D}_{\mathrm{xy}} \\
\mathrm{D}_{\mathrm{yx}} & \mathrm{D}_{\mathrm{yy}}
\end{array}\right]=\frac{\Im\left\{\left[\mathbf{H}_{b}(i \omega)\right]\right\}}{\omega}}
\end{aligned}
$$

\section{Experimental Procedure}

The bearing dynamic coefficients are identified in the frequency range $15-130 \mathrm{~Hz}$. A reference operational 
Table 2. Main parameters for the lubrication regimes featured with the ALB.

\begin{tabular}{ccccccc}
\hline & & & \multicolumn{2}{c}{ PD-controller \#1 } & P-controller \#2 \\
Lub. Regime & $\Omega[\mathrm{rpm}]$ & $P_{i n j}[\mathrm{bar}]$ & Injection & $k_{p}[\mathrm{kV} / \mathrm{m}]$ & $k_{d}[\mathrm{Vs} / \mathrm{m}]$ & $k_{p_{1}} / k_{p_{2}}[\mathrm{kV} / \mathrm{m}]$ \\
\hline Passive & 3000 & - & - & - & - & - \\
Hybrid & 3000 & 85 & Leakage & - & - & - \\
Hybrid & 3000 & 85 & Upwd $(15 \mu \mathrm{m})$ & - & - & - \\
Hybrid & 3000 & 85 & Dwnwd $(30 \mu \mathrm{m})$ & - & - & - \\
Active \#1 & 3000 & 85 & - & -30 & +20 & - \\
Active \#2 & 3000 & 85 & - & - & - & $+30 /-30$ \\
\hline
\end{tabular}

condition is used: angular velocity of $3000 \mathrm{rpm}$ and almost null load on the ALB. Such a load condition is realized aided by the magnetic bearing. As already mentioned, such a condition has been selected with the goal of mimicking a rotor under light load condition. Although magnetic bearings introduce negative stiffness in open-loop configuration, its magnitude is approx. 100 times smaller than the ones to be identified, hence its contribution to the whole system dynamics can be neglected without loss of stringency. This can be corroborated either experimentally or theoretically ${ }^{39}$. A supply pressure of 85 bar has been used for the active control system. Such a relative high pressure is set in order to make the hydrostatic effect more notorious in the bearing and to keep the cut-off frequency of the servovalves out of the frequency range of study $(260 \mathrm{~Hz}$ with approx. 100 bar). It is also slightly higher than the pressure used in the modelling, trying to account for measurement errors and pressure losses in the hydraulic system. For all lubrication regime cases, care is taken to guarantee that the test rig reaches thermal and geometric steady-state equilibria.

To ensure only vertical journal movements under the hybrid lubrication regime, i.e. upward and downward cases, an I-controller with gain of $k_{i}=-30 \mathrm{kV} /(\mathrm{ms})$ is used. The maximum vertical displacement from the equilibrium position is $+15 \mu \mathrm{m}$ upward and $-30 \mu \mathrm{m}$ downward. Two types of control laws are implemented and presented below based on a PD-controller and a P-controller. Their gain values are summarized in Table 2 together with the main parameters of all lubrication regimes used. The experimental procedure to synthesize the proportional $k_{p}$ and derivative $k_{d}$ gains for the feedback-controlled lubrication regime is thoroughly explained by Salazar and Santos ${ }^{35}$.

\section{Feedback-Controlled Lubrication - Control Laws}

Control Law \#1 If the simplest control law is considered, only a pair of control gains $\left(k_{p}, k_{d}\right)$ must be determined. Despite such an advantage, an important drawback is obtained by using the same control gains to govern both servovalves. Their dynamics cannot be independently managed. The servovalve control signals $\left\{\begin{array}{ll}u_{1} & u_{2}\end{array}\right\}^{T}$ can be obtained in terms of the measured displacement as ${ }^{35}$ :

$$
\left\{\begin{array}{l}
u_{1} \\
u_{2}
\end{array}\right\}=-k_{p}\left[\begin{array}{cc}
1 & 1 \\
-1 & 1
\end{array}\right]\left\{\begin{array}{l}
x_{\mathrm{P}} \\
y_{\mathrm{P}}
\end{array}\right\}-k_{d}\left[\begin{array}{cc}
1 & 1 \\
-1 & 1
\end{array}\right]\left\{\begin{array}{l}
\dot{x}_{\mathrm{P}} \\
\dot{y}_{\mathrm{P}}
\end{array}\right\}
$$

where $\left\{\begin{array}{ll}x_{\mathrm{P}} & y_{\mathrm{P}}\end{array}\right\}^{T}$ and $\left\{\dot{x}_{\mathrm{P}} \dot{y}_{\mathrm{P}}\right\}^{T}$ stand for the feedback control signals of rotor lateral displacement and velocity at point $\mathrm{P}$ respectively. To determine the velocity signals, the displacement signals are low-pass filtered and then numerically differentiated. Under the simplifying assumption of a frequency independent relationship between the control signals and the fluid film active forces, the control law \#1 influences predominantly the cross coupling coefficients rather than the direct ones. See appendix A. Although the effect of increasing the cross coupling coefficients does not lead to any benefit to the rotor-bearing system dynamics, it illustrates the capability of influencing the bearing force coefficients, which is one of the work goals.

Control Law \#2: A more aggressive control law can be chosen for modifying the direct coefficients. However, additional gains for the controller must be determined. If the following proportional control law is used, then only a pair of proportional gains $\left(k_{p_{1}}, k_{p_{2}}\right)$ for the P-controller must be synthesized. This control law \#2 allows us to command the servovalves as:

$$
\left\{\begin{array}{l}
u_{1} \\
u_{2}
\end{array}\right\}=-\left[\begin{array}{cc}
k_{p_{1}} & k_{p_{2}} \\
r k_{p_{1}} & -k_{p_{2}}
\end{array}\right]\left\{\begin{array}{l}
x_{\mathrm{P}} \\
y_{\mathrm{P}}
\end{array}\right\}
$$

where $r$ is a constant identified in the experimental gain matrix which relates the control signals with the active forces. It is shown in appendix A, under the same simplifying assumption adopted, that each gain $k_{p_{i}}$ modifies the direct stiffness coefficients, and that the cross stiffness coefficients stay unaltered. Since the derivative gains $k_{d_{i}}$ are disregarded, the bearing damping properties are not affected. This control law can be beneficial for the rotor-bearing system since it can be used to increase the asymmetry of the bearing direct force coefficients while not affecting the cross coupling ones.

\section{Uncertainty Analysis}

To estimate the interval (normally, with $95 \%$ of confidence) on which the results are thought to lie, the total uncertainty of the identified coefficients is calculated as proposed by Moffat $^{31}$ following the ISO GUM ${ }^{40}$ recommendations. It is considered that measurement random uncertainties in the FRFs are not influencing the results, and this work only accounts for measurement and modelling systematic uncertainties. A large amount of FRFs averages is considered to minimize their standard deviation and to work with their mean values as their best estimates. Referring to Equation (1) the modelling uncertainties arise from the determination of the system dynamic stiffness $\left[\mathbf{Z}_{\mathbf{0}}\right]$ and from the length of the finite elements. 
Table 3. Model parameters considered for the uncertainty evaluation.

\begin{tabular}{|c|c|c|c|c|c|c|c|c|c|}
\hline Param. & $\begin{array}{l}\text { Mean } \\
\text { Value }\end{array}$ & Source & $\begin{array}{l}\text { Error } \\
\text { Limits }\end{array}$ & $\begin{array}{c}\text { Standard } \\
\text { Uncertainty }\end{array}$ & Param. & $\begin{array}{l}\text { Mean } \\
\text { Value }\end{array}$ & Source & $\begin{array}{l}\text { Error } \\
\text { Limits }\end{array}$ & $\begin{array}{c}\text { Standard } \\
\text { Uncertainty }\end{array}$ \\
\hline $\mathrm{M}^{\mathrm{S}}$ & $49.55 \mathrm{~kg}$ & CAD file & $\pm 1 \%$ & $\pm 0.2528 \mathrm{~kg}$ & $l_{\mathrm{BP}}$ & $1.0015 \mathrm{~m}$ & Measured & $\pm 0.005 \mathrm{~m}$ & $0.0029 \mathrm{~m}$ \\
\hline $\mathrm{M}^{\mathrm{R}}$ & $6.48 \mathrm{~kg}$ & Measured & $\pm 0.020 \mathrm{~kg}$ & $\pm 0.0115 \mathrm{~kg}$ & $l_{\mathrm{BE}}$ & $1.0790 \mathrm{~m}$ & CAD file & $\pm 1 \%$ & $0.00551 \mathrm{~m}$ \\
\hline $\mathrm{M}^{\mathrm{E}}$ & $1.1124 \mathrm{~kg}$ & Measured & $\pm 0.0020 \mathrm{~kg}$ & $\pm 0.0112 \mathrm{~kg}$ & $\mathrm{r}^{\mathrm{S}}$ & A & CAD file & $\pm 1 \%$ & $0.01 A / 1.96$ \\
\hline$l_{\mathrm{BR}}$ & $0.4850 \mathrm{~m}$ & Measured & $\pm 0.005 \mathrm{~m}$ & $\pm 0.0029 \mathrm{~m}$ & $r^{R, E}$ & $A$ & Estimated & $\pm 3 \%$ & $0.03 A / 1.96$ \\
\hline $\mathrm{l}_{\mathrm{BT}}$ & $0.7315 \mathrm{~m}$ & CAD file & $\pm 1 \%$ & $\pm 0.0037 \mathrm{~m}$ & & & & & \\
\hline
\end{tabular}

Table 3 summarizes all parameters considered for the evaluation of the uncertainty along with their mean values, sources, error limits and standard uncertainties. Uncertainties in the inertia are evaluated considering the uncertainties in their respective radius of mean value $A$. For the measured parameters, their error limits are obtained from their instruments whilst for the case of parameters obtained from CAD files their errors are estimated to be lower than $1 \%$. In the case of estimated radius a bigger error of $3 \%$ is considered. A normal distribution with a $95 \%$ confidence interval level is considered for all parameters, except for the measured ones, for which a uniform distribution with $100 \%$ confidence interval level is considered. Regarding the transducers, the load cell manufacturer informs linearity of $\pm 1 \%$ at maximum load while for the proximity probe a linearity of $\pm 3 \%$ is estimated based on a similar transducer. For both sources of uncertainty, a normal distribution with $95 \%$ confidence level is taken into account. Finally, a normal distribution with a confidence level of $95 \%$ is considered to calculate the expanded uncertainty of results.

The parameters which strongly contribute to the total uncertainty are: the transducer sensitivities and lengths, particularly the displacement sensor sensitivity and the distances $\mathrm{l}_{\mathrm{BT}}$ and $\mathrm{l}_{\mathrm{BE}}$. In general, acceptable values of the expanded uncertainties are obtained which are to be presented simultaneously with the results.

\section{Rotor-Bearing System Response. Experimental FRFs}

Insight into the overall system behaviour can be obtained by analyzing the experimental FRFs under several lubrication regimes. Moreover, such FRFs are fundamental for bearing parameter identification. Four representative cases are presented: the passive and the hybrid (leakage case) lubrication regimes in Figure 5 and two feedback-control lubrication regimes in Figure 6. These FRFs are obtained with the aid of an electromagnetic shaker by sweeping a linear bidirectional chirp excitation from 15 to $130 \mathrm{~Hz}$ with a target time of 45 seconds for 10 minutes. All signals are simultaneously sampled at a frequency of $6000 \mathrm{~Hz}$. The FRFs are calculated by means of the $\mathrm{H} 1$ estimator, 20,000 samples, an overlap of $80 \%$ and flattop windowing. Shaft displacements were recorded with $8 \mathrm{mV} / \mu \mathrm{m}$ eddy-current inductive sensors with $2 \mathrm{~mm}$ linear range, ranging between 30-50 $\mu \mathrm{m}$.

The used test setup configuration entails that the dynamic forces are exerted in the excitation bearing (point E) and the system response is measured in the proximity probe location (point P). If the passive FRFs, presented in Figure 5(a), are used as reference, it is noted that the rotor lateral vibration amplitudes are drastically reduced when the hybrid lubrication is activated, Figure 5(b), leading to significant damping improvement in the frequency range analysed. Comparing the FRFs of Figure 6 with ones of Figure 5 it can be clearly noticed that depending on the adopted control law the rotor amplitude can be either reduced or increased. It is clear that the control law \#1, Figure 6(a), generates a resonant zone around $60 \mathrm{~Hz}$ whereas the control law \#2, Figure 6(b), produces a further reduction of the amplitude below $100 \mathrm{~Hz}$. The implications of these FRFs in terms of bearing force coefficients are presented next.

\section{Bearing Force Coefficients - Passive and Leakage Cases}

Figure 7 shows the identified force coefficients for the ALB under passive and hybrid lubrication regimes in the frequency range studied. Such results are obtained using the FRFs presented in Figure 5. Generally speaking, the stiffness coefficients for the passive case (dashed lines) can be considered almost constant in the whole frequency range used. With regards to the expanded uncertainty, low values are obtained with the largest one at about $\pm 20 \%$ for the $\mathrm{K}_{\mathrm{yx}}$ term. Comparing with theoretical coefficients, good agreement for the direct stiffness coefficients is found. However large discrepancies for cross coupling stiffness coefficients are shown, for which the model predicts almost null cross coupling coefficients. The cross coupling stiffness coefficients are negative and have the same order of magnitude, i.e. $10^{7}$, when compared to the direct ones. The strong cross coupling effect is fundamentally detected only under light load conditions. To further investigate it, two additional experiments are carried out and reported in appendix B. Firstly, to eliminate the hypothesis of starving lubrication and consequently generating a cross coupling effect followed by reducing damping coefficients, several supply pressure and flow conditions are tested. The cross coupling coefficients are not significantly affected for any of these cases. Secondly, $900 \mathrm{~N}$ downward load is applied to the shaft via AMB. For such a new loading condition, the cross coupling coefficients are reduced. Other authors, such as Childs and Carter ${ }^{19}$ and Rodriguez and Childs ${ }^{41}$, also report cross coupling coefficients within the same order of magnitude as the direct ones, although those experiments do not correspond to the same TPJB design and load conditions.

Back to Figure 7(b), it can be seen that the damping coefficients weakly depend on the frequency for the passive case. Due to light load condition, their values are small, i.e. in the order of $10^{4}$, especially for frequencies over 
(a) Passive Lubrication
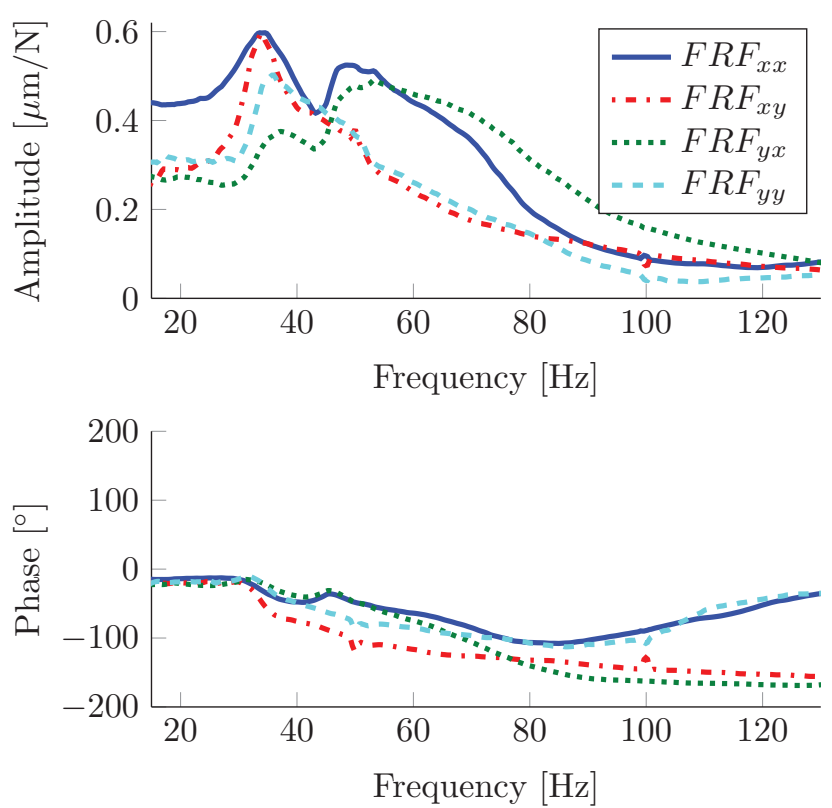

(b) Hybrid Lubrication. Leakage Case
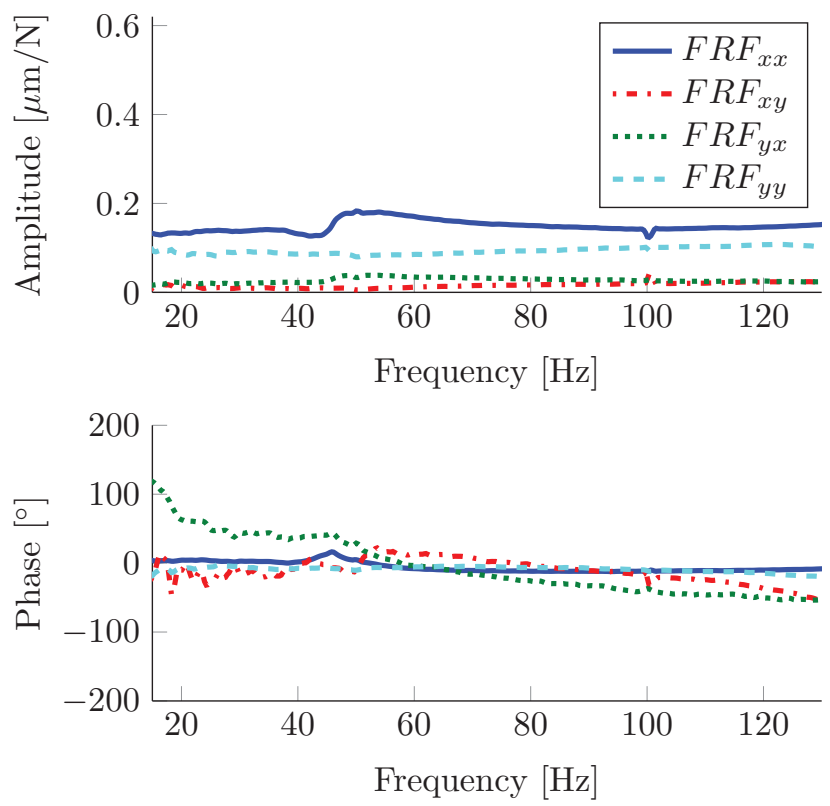

Figure 5. Measured FRFs, between the excitation point $(E)$ and the measurement point $(P)$, used for dynamic parameter identification. (a): ALB under passive lubrication regime. (b): ALB under Leakage lubrication regime. Solid line (-): $F R F_{x x}$, dash-dot line (-.): $F R F_{x y}$, dotted line (..): $F R F_{y x}$, dashed line (--): $F R F_{y y}$.

(a) Feedback-Controlled Lubrication

PD-Controller \#1
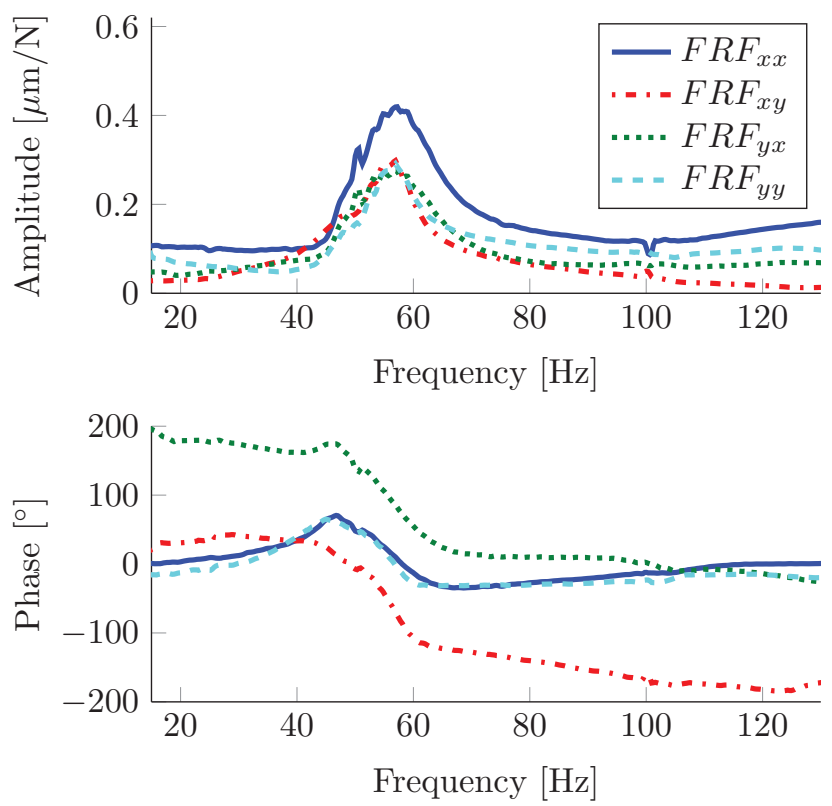

(b) Feedback-Controlled Lubrication

P-Controller \#2
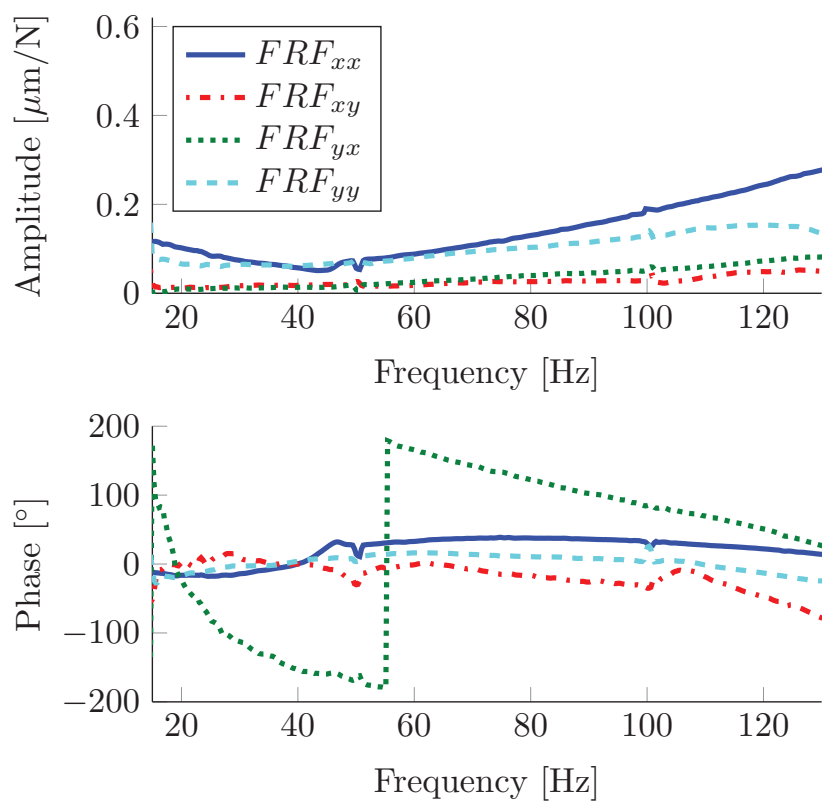

Figure 6. Measured FRFs, between the excitation point $(E)$ and the measurement point $(P)$, used for dynamic parameter identification. ALB under feedback-controlled lubrication regime. (a): PD-controller with control law \#1. (b): P-controller with control law \#2. Solid line (-): $F R F_{x x}$, dash-dot line (-.): $F R F_{x y}$, dotted line (..): $F R F_{y x}$, dashed line (--): $F R F_{y y}$.

$40 \mathrm{~Hz}$. The experimental results are little affected by the expanded uncertainty. Comparison of the experimental damping coefficients against the predicted ones shows poor agreement, which set some room for modelling improvements. It is important to underline here that, the work goal is to demonstrate experimentally the modification of the bearing force coefficients due to active lubrication and not to, from any point of view, validate the theoretical model.

In Figure 7 (c) and (d) the bearing dynamic coefficients for the leakage case are illustrated using solid lines. Comparing the passive and the leakage lubrication cases, it becomes evident that the vertical direct stiffness coefficient $K_{y y}$ significantly increases its value to about $7.5 \cdot 10^{7} \mathrm{~N} / \mathrm{m}$ above $50 \mathrm{~Hz}$, while the values of the horizontal direct 
(a)

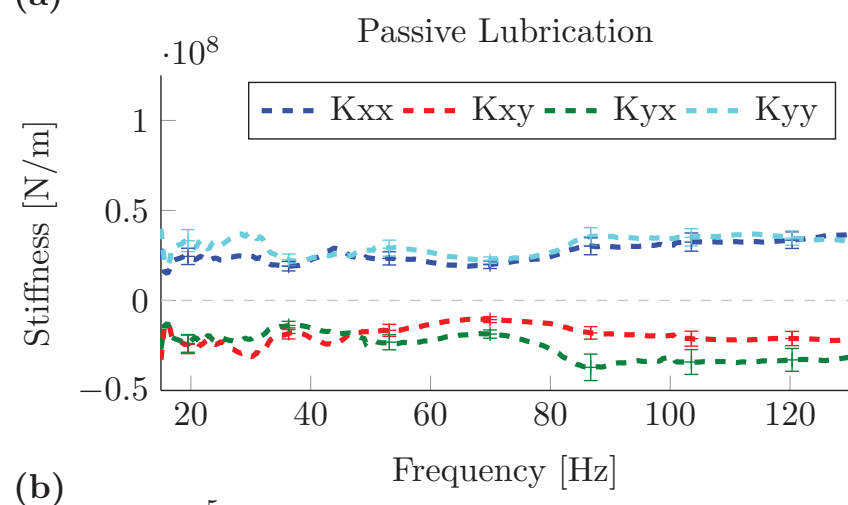

(b)

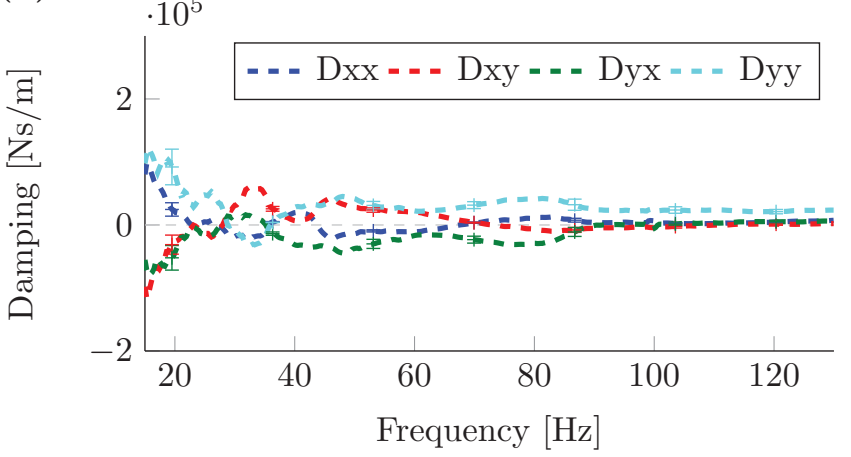

(c)

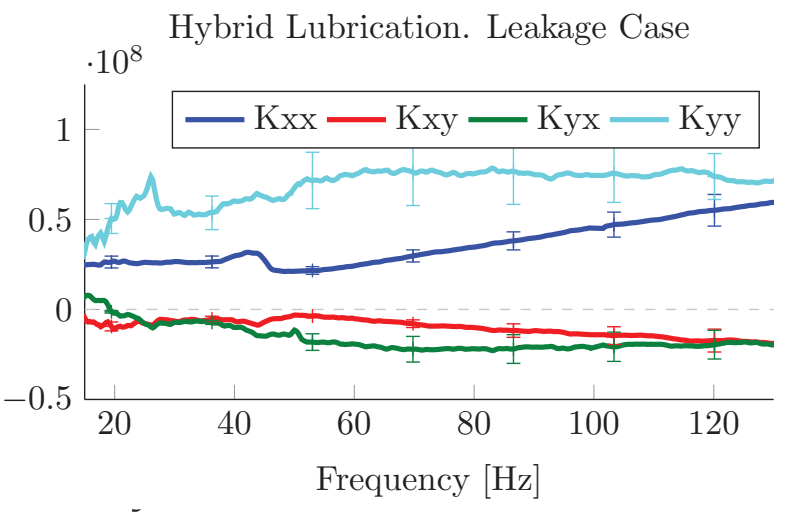

(d)

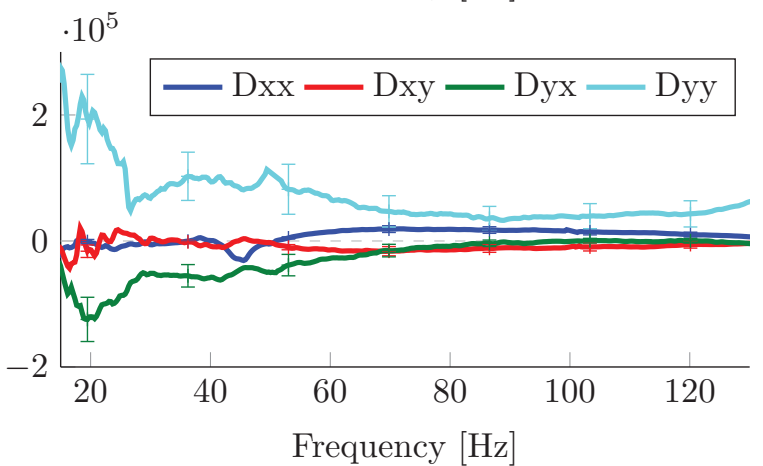

Figure 7. Identified dynamic coefficients for the ALB. (a) and (b): ALB under passive lubrication regime (dashed lines (--)). (c) and (d): ALB under hybrid lubrication regime, the leakage case (solid lines (-)).

stiffness coefficient $K_{\mathrm{xx}}$ remain almost the same, i.e. the bearing becomes more asymmetric. For $\mathrm{K}_{\mathrm{xx}}$, a stronger frequency dependency is seen after $50 \mathrm{~Hz}$. Comparing the passive and the leakage lubrication cases, it can be seen that the cross coupling coefficients are significantly reduced for the hybrid case. The expanded uncertainty becomes more important as the frequency increases and it is far more important for the vertical direct stiffness coefficient $\mathrm{K}_{\mathrm{yy}}$ with a magnitude of about $\pm 17 \%$. In the case of the damping coefficients, Figure $7(d)$, it is noticed that the bearing becomes more damped, especially in the vertical direction, i.e. increased value of $\mathrm{D}_{\mathrm{yy}}$. Moreover, all damping coefficients significantly diminish from $10^{5}$ to $10^{4}$ over the frequency span of $60 \mathrm{~Hz}$. In the horizontal direction, at low frequencies, the damping coefficients $D_{x x}$ and $D_{x y}$ are significantly smaller than those in the vertical direction. Over $60 \mathrm{~Hz}, \mathrm{D}_{\mathrm{yy}}$ provides the largest damping to the system while the cross coupling coefficients $D_{x y}$ and $\mathrm{D}_{\mathrm{yx}}$ are negative. Considering the damping coefficients, the expanded uncertainty is more significant for the direct coefficient $\mathrm{D}_{\mathrm{yy}}$ at low frequencies where it reaches $\pm 37 \%$.

\section{Bearing Force Coefficients - Hybrid Cases}

Figure 8 depicts comparative plots of the identified dynamic properties of the ALB for all hybrid lubrication regimes, i.e., for the leakage, upward and downward injection cases. The leakage case, plotted in solid lines, is used as a benchmark, while the upward and downward cases are plotted with dotted and dashed lines, respectively. Although it can be argued that all differences among the cases lie within the confidence limits, it is clear that the vertical direct stiffness coefficient $\mathrm{K}_{\mathrm{yy}}$ is reduced when the shaft is moved upward, closer to the bearing center, which turns the ALB softer in the vertical direction. In the downward injection case the cross coupling coefficients are significantly reduced for frequencies higher than $50 \mathrm{~Hz}$ and are simultaneously less influenced by uncertainties. Regarding the damping coefficients, there are no significant differences between the different hybrid cases and they behave similarly within the uncertainty bounds. Hence, it can be stated that the damping is hardly affected by the mentioned changes under these different hybrid lubrication conditions. Comparison against theoretical results of Figure 3(b) shows fair agreement in the sense that theoretical as well as experimental stiffness and damping coefficients increase their values when compared against the passive case. However, comparing upward against leakage case, a softening effect in the vertical direction can be observed. Such an experimental finding though is hardly predicted by the theoretical model. Furthermore, among the three hybrid lubrication cases, the leakage case shows the largest discrepancies between simulations and experiments, see Figure 7(c) and (d). Further efforts towards theoretical modelling improvements are necessary.

\section{Bearing Force Coefficients - Feedback-Controlled Cases}

Figure 9 shows selected results for the identified coefficients under the feedback-controlled lubrication regimes in the frequency range of 60-130 Hz. Figures 9(a) and (b) show the results obtained with the active lubrication defined by the control law \#1, i.e. a PD-controller and Figures 9(c) and (d) the coefficients obtained using the control law \#2, a Pcontroller. Gains of both control laws are summarized in 
(a)

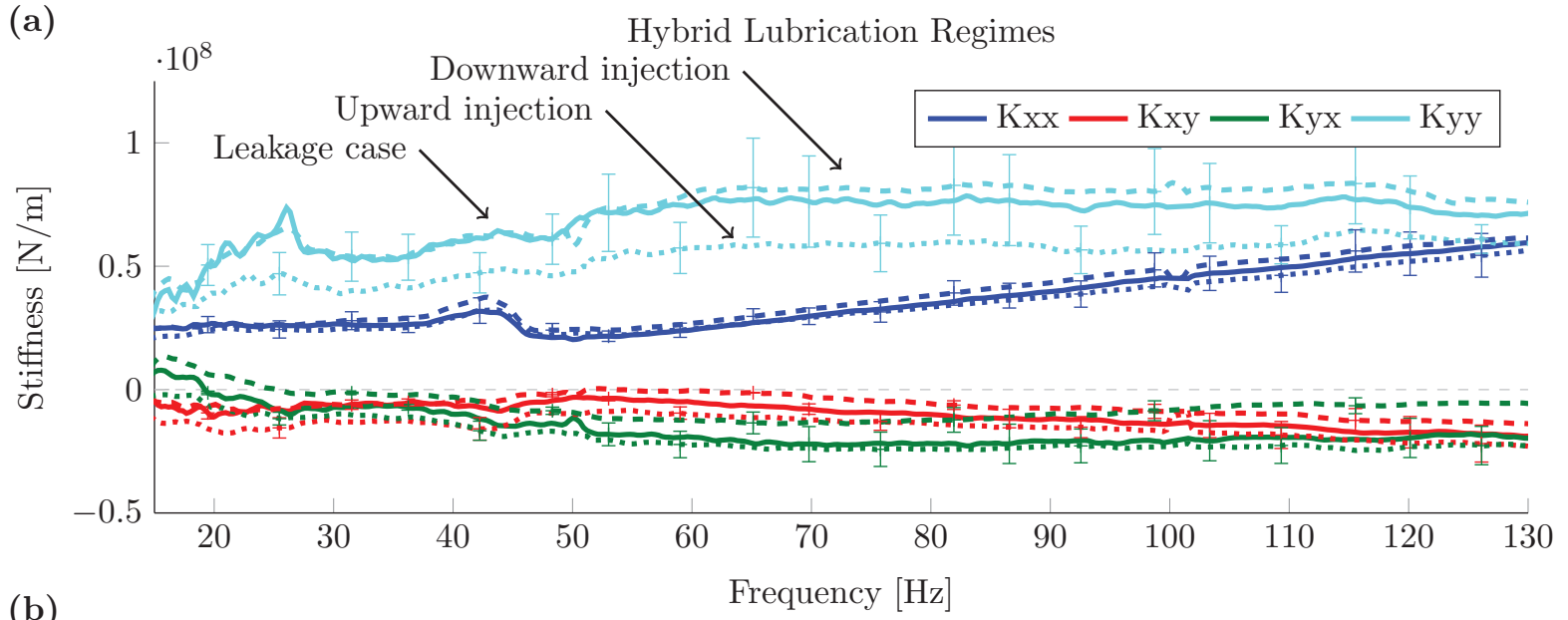

(b)

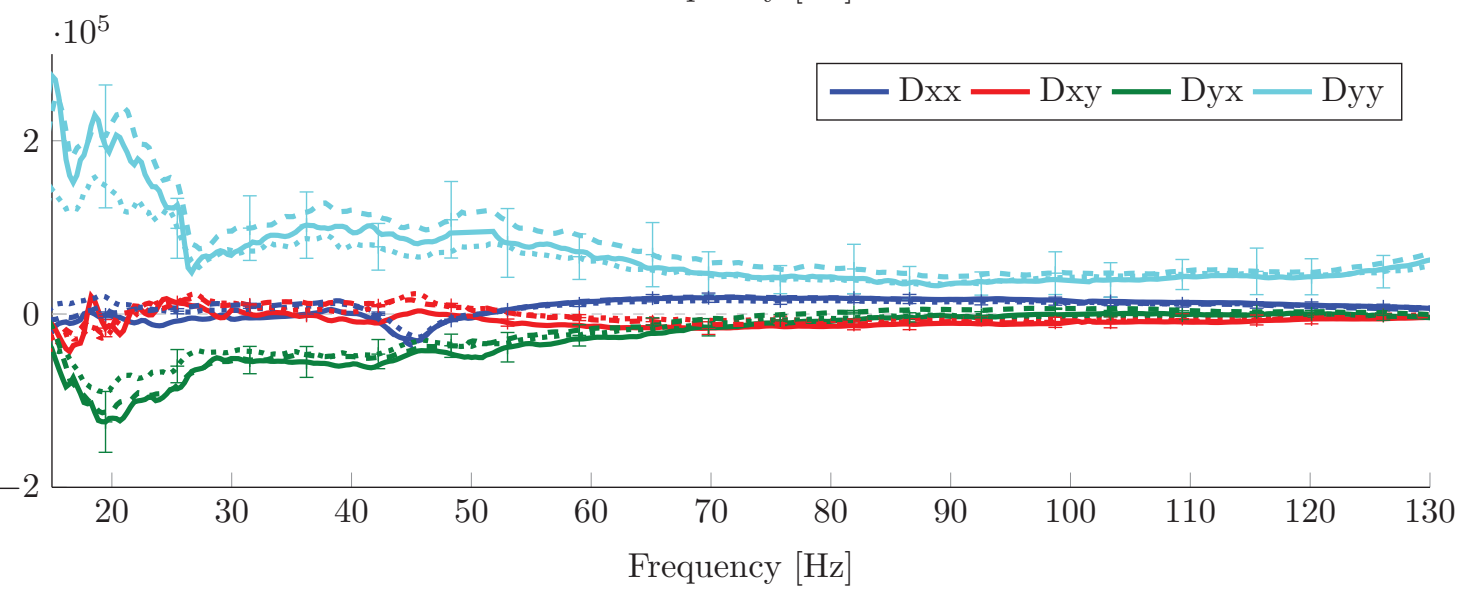

Figure 8. Comparison of the identified dynamic coefficients under the different hybrid lubrication regimes. (a): Stiffness force coefficients. (b): Damping force coefficients. Solid line (-): Leakage case. Dotted Line (..): Upward injection aided by I-controller. Dashed Line (--): Downward injection aided by I-controller.

Table 2. As a benchmark, the coefficients obtained for the leakage case are added with thin solid lines.

Using the PD-controller \#1 (dashed lines) the direct stiffness coefficients (Figure 9(a)) have a constant behaviour over the frequency range investigated, suppressing the frequency dependency of $\mathrm{K}_{\mathrm{xx}}$ seen under the leakage case. The cross coupling coefficients, as aforementioned, are strongly affected by the control law adopted. Indeed, this particular behaviour is also theoretically reproduced as seen in Figure 3(c) and (d). Between $60-80 \mathrm{~Hz}$ large uncertainties can be detected for both direct coefficients with maximum confidence limit of $\pm 37 \%$. For the cross coupling coefficient $\mathrm{K}_{\mathrm{yx}}$ smaller uncertainties are found in the whole frequency span analysed. The same behaviour is observed for the damping coefficients, i.e. the direct damping coefficients vary significantly when compared to the one obtained in the leakage case and the cross coupling damping coefficients are the ones mostly affected by the controller. Large uncertainty of about $40 \%$ is seen for the cross coupling damping coefficients, especially between $60-80 \mathrm{~Hz}$. The cross coupling stiffness coefficients are less affected by the controller \#2 (dotted lines) in comparison with controller \#1, see Figure 9(c). The direct stiffness coefficients are the most affected by the control law \#2, leading to a reduction of the direct stiffness coefficients, as it was pursued. Damping coefficients, see Figure 9(d), are also modified by the control law, even though the featured controller is a P-controller.

\section{Conclusions}

The contribution of this paper is mainly experimental in nature. It should be re-emphasized that the work goal was to show the modification of the bearing dynamic properties via the active lubrication and it should not be seen, under any case, as an attempt to validate the theoretical bearing coefficients. Having said that and keeping in mind the lightload condition imposed on a bearing supporting a "flexible" rotor, the comparison between theoretical and experimental results shows a fair agreement for a reduced number of cases only. This suggests the need for further improvements of the multiphysics modelling of the ALB and of the identification modelling as well. In the first case, the way how all different regimes are modelled should be further investigated and in the second case, the extension of the identification modelling to account for further dynamics, such as, for instance, foundation and hydraulic dynamics shall be included if needed. Currently, both approaches are being researched.

Again, heading towards the research goal and in the light of the experimental investigations followed by comprehensive uncertainty analysis, it can be concluded that: 
(a)

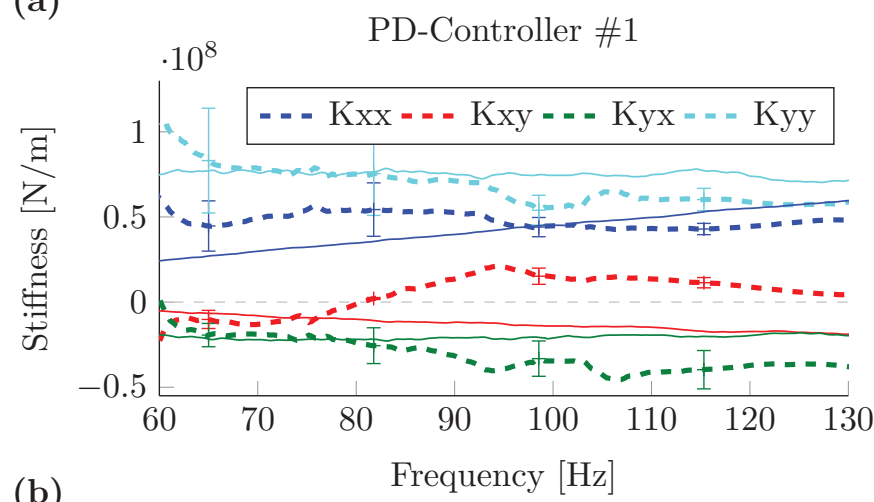

(b)

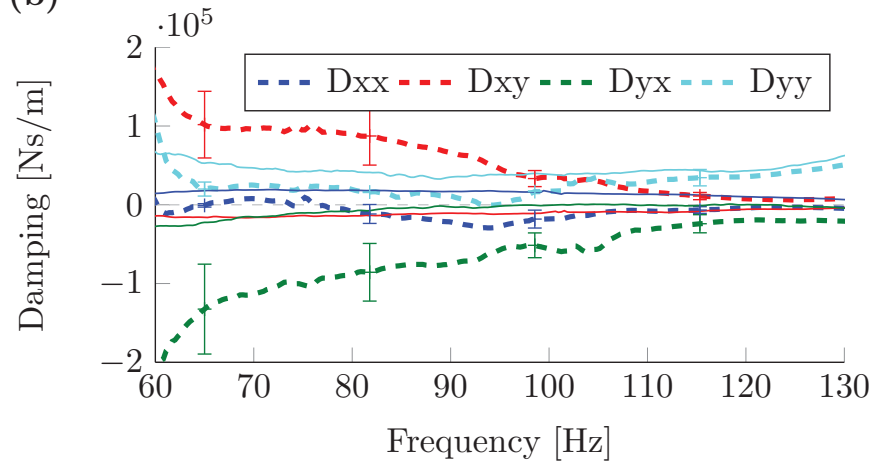

(c)

Feedback-Controlled Lubrication

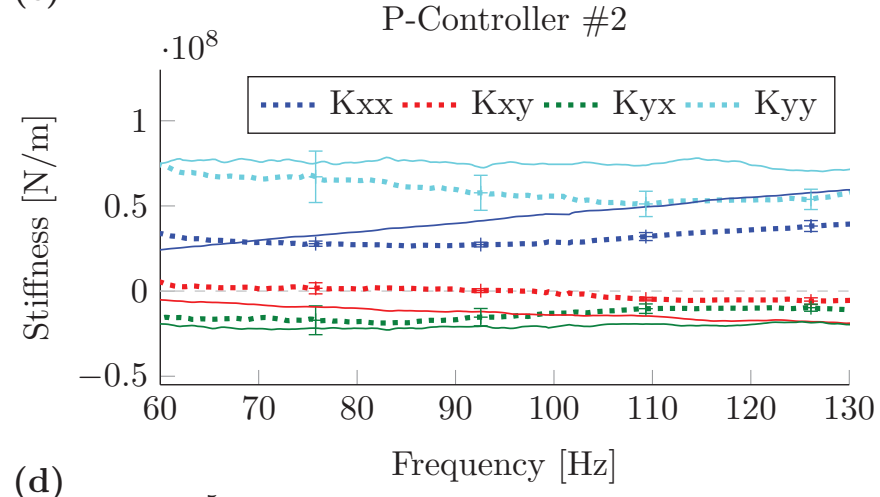

(d)

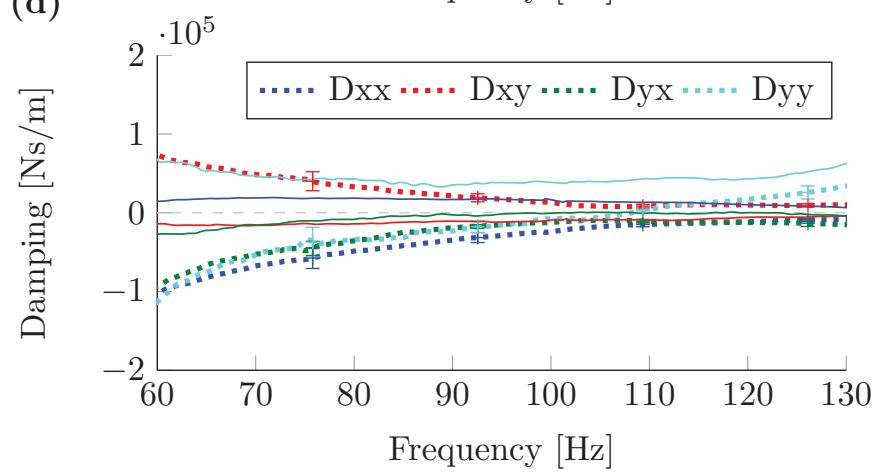

Figure 9. Identified dynamic coefficients for the ALB. (a) and (b): ALB under feedback-controlled lubrication regime, control law \#1 (dashed lines (--)), $k_{p}=-30 \mathrm{kV} / \mathrm{m} \& k_{d}=20 \mathrm{Vs} / \mathrm{m}$. (c) and (d): ALB under feedback-controlled lubrication regime, control law \#2 (dotted lines $(\cdot \cdot)), k_{p_{1}}=-30 \mathrm{kV} / \mathrm{m} \& k_{p_{2}}=-30 \mathrm{kV} / \mathrm{m}$. Results obtained under the leakage hybrid case are superimposed with solid lines $(-)$ as a benchmark.

- The development of the hybrid or feedback-controlled lubrication regimes clearly modify the rotor-bearing system properties as a whole, significantly reducing the rotor vibration amplitudes. This can be clearly seen from the FRFs used to identify the bearing coefficients under several lubrication conditions.

- The stiffness coefficients identified under passive lubrication show weak frequency dependency in the whole range of study. Considering the direct stiffness coefficients, good agreement between simulated and experimental results is found. Nevertheless, it is not the case for the cross coupling stiffness coefficients.

- The hybrid lubrication regimes can increase the bearing stiffness asymmetry and significantly contribute to reducing the cross coupling coefficients identified under light load conditions. Furthermore, under these lubrication regimes, the ALB becomes more damped.

- The hybrid lubrication regimes also allow us to modify the direct stiffness coefficients by changing the journal equilibrium position aided by I-controllers. A softening of the vertical direct stiffness coefficient - in comparison to the leakage case - can be observed, due to the shaft lifting to a more centred equilibrium position.

- The feedback-controlled lubrication clearly modifies the ALB dynamic properties and can be developed using classical PD controllers. By properly choosing the control law and gains, beneficial modification of the rotor-bearing system dynamic properties can be achieved. It was shown that different control laws can produce different effects on the direct and cross coupling force coefficients.

\section{Acknowledgments}

The authors would like to express their deepest acknowledgments to Mr. Alejandro Cerda Varela for his valuable support during the experimental tests and fruitful discussions on the matter.

\section{References}

1. Hagg AC. The influence of oil-film journal bearings on the stability of rotating machines. Journal of Applied Mechanics, Transactions of the ASME 1946; 13(3): A211-A220.

2. Someya T. Journal-Bearing Databook. Springer-Verlag, 1988. ISBN 3-540-17074-X.

3. Santos IF. Design and Evaluation of Two Types of Active Tilting Pad Journal Bearings. In CRBurrows and PSKeogh (eds.) The Active Control of Vibration. London, England: Mechanical Engineering Publications Limited, 1994. pp. 7987.

4. Santos IF and Russo F. Tilting-Pad Journal Bearings with Electronic Radial Oil Injection. Journal of Tribology, ASME Trans 1998; 120(3): 583-594.

5. Nicoletti R and Santos IF. Linear and non-linear control techniques applied to actively lubricated journal bearings. Journal of Sound and Vibration 2003; 260(5): 927-947.

6. Santos IF and Scalabrin A. Control System Design for Active Lubrication With Theoretical and Experimental Examples. 
Journal of Engineering for Gas Turbines and Power 2003; 125(1): 75-80.

7. Santos IF, Nicoletti $R$ and Scalabrin A. Feasibility of Applying Active Lubrication to Reduce Vibration in Industrial Compressors. Journal of engineering for Gas Turbines and Power 2004; 126(October): 848-854.

8. Nicoletti R and Santos IF. Frequency Response Analysis of an Actively Lubricated Rotor/Tilting-Pad Bearing System. ASME Journal of Engineering for Gas Turbines and Power 2005; 127: 638-645.

9. Nicoletti R and Santos IF. Control System Design for Flexible Rotors Supported by Actively Lubricated Bearings. Journal of Vibration and Control 2008; 14(3): 347-374.

10. Allaire P, Parsell J and Barrett L. A Pad Perturbation Method for the Dynamic Coefficients of Tilting-Pad Journal Bearings. Wear 1981; 72: 29-44.

11. Haugaard AM and Santos IF. Elastohydrodynamics Applied to Active Tilting-Pad Journal Bearings. Journal of Tribology 2010; 132(2): 021702-1-10.

12. Springer H. Dynamic characteristics of sliding bearings with movable segments. VDI-Berichte 1980; 381: 177-184.

13. Santos IF. Theoretical and Experimental Identification of the Stiffness and Damping Coefficients of Active-Tilting Pad Journal Bearings. In Friswell $\mathrm{M}$ and Mottershead J (eds.) Identification in Engineering Systems. Swansea, Great Britain: The Cromwell Press Ltd., 1996. pp. 325-334.

14. Dmochowski W. Dynamic Properties of Tilting-Pad Journal Bearings: Experimental and Theoretical Investigation of Frequency Effects due to Pivot Flexibility. ASME Journal of Engineering for Gas Turbines and Power 2007; 129: 865-869.

15. Wilkes $\mathbf{J}$ and Childs D. Tilting Pad Journal Bearings - A Discussion on Stability Calculation, Frequency Dependence and Pad and Pivot. ASME Journal of Engineering for Gas Turbines and Power 2012; 134

16. San Andres L and Tao Y. The Role of Pivot Stiffness on the Dynamic Force coefficients of Tilting Pad Journal Bearings. ASME Journal of Engineering for Gas Turbines and Power 2013; 135.

17. Brockwell K, Kleinbub D and Dmochowski W. Measurement and Calculation of the Dynamic Operating Characteristics of the Five Shoe Tilting-Pad Journal Bearing. STLE Tribology Transactions 1989; 33(4): 481-492.

18. Ha H and Yang S. Excitation Frequency Effects on the Stiffness and Damping Coefficients of a Five Pad Tilting Pad Journal Bearing. ASME Journal of Tribology 1999; 121(3): 517-522.

19. Childs D and Carter C. Rotordynamics Characteristics of a Five Pad, Rocker-Pivot, Tilting Pad Bearing in a Load-on-Pad Configuration; Comparisons to Predictions and Load-BetweenPad Results. ASME Journal of Engineering for Gas Turbines and Power 2011; 133.

20. Kulhanek C and Childs D. Measured Static and Rotordynamic Coefficients Results for a Rocker-Pivot, Tilting-Pad Bearing with $50 \%$ and $60 \%$ offsets. ASME Journal of Engineering for Gas Turbines and Power 2012; 134.

21. Rouvas C and Childs D. A Parameter Identification Method for the Rotordynamic Coefficients of a High Reynolds Number Hydrostatic Bearing. ASME Journal of Vibrations and Acoustics 1993; 115: 264-270.

22. Glienicke J. Experimental Investigation of Stiffness and Damping of Turbine Bearings and their Application to Instability Predictions. ProcImechE 1966; 181(3B): 116-129.
23. Arumugam P, Swarnamani S and Prabhu BS Experimental identification of linearized oil film coefficients of cylindrical and tilting pads bearings. Journal of Engineering for Gas Turbines and Power 1995; 117: 593-599.

24. Wang Q and Maslen E. Identification of Frequency-Dependent Parameters in a Flexible Rotor System. ASME Journal of Engineering for Gas Turbines and Power 2006; 128: 670-676.

25. Cerda Varela A and Santos IF. Dynamic Coefficients of a Tilting Pad with Active Lubrication: Comparison between Theoretical and Experimental Results. Journal of Tribology 2015; 137: 031704-1-031704-12.

26. Simmons GF, Cha M, Aidanpaa JO et al. Steady state and dynamic characteristics for guide bearings of a hydro-electric unit. Proceedings of the Institution of Mechanical Engineers, Part J: Journal of Engineering Tribology 2014; 228(8): 836848.

27. Olsson KO. Some fundamental aspects on the dynamic properties of journal bearings. In Sixth International Conference on Vibrations in Rotating Machinery, IMechE, London, UK. pp. 31-40.

28. White MF and Chan SH. The Subsynchronous Dynamic Behaviour of Tilting-Pad Journal Bearings. Journal of Tribology 1992; 114(January): 167.

29. Flack RD and Zuck CJ. Experiments on the Stability of Two Flexible Rotors in Tilting Pad Bearings. Tribology Transactions 1988; 31(January 2015): 251-257.

30. Lie Y, You-Bai X, Jun Z et al. Experiments on the destabilizing factors in tilting pad bearings. Tribology International 1989; 22: 329-334.

31. Moffat R. Describing the Uncertainties in Experimental Results. Experimental Thermal and Fluid Science 1988; 1: 317.

32. Kjølhede, Klaus and Santos, Ilmar F. Experimental contribution to high-precision characterization of magnetic forces in active magnetic bearings. ASME Journal of Engineering for Gas Turbines and Power 2007; 129(2): 503510 .

33. Salazar JG and Santos IF. Exploring integral controllers in actively-lubricated tilting- pad journal bearings. Proc IMechE Part J: J Engineering Tribology 2015; 229(7): 835-848;

34. Merritt, Herbert E. Hydraulic control systems. John Wiley \& Sons, 1967.

35. Salazar JG and Santos IF. Feedback-controlled lubrication for reducing the lateral vibration of flexible rotors supported by tilting-pad journal bearings. Proc IMechE Part J: $J$ Engineering Tribology first published on April 6, 2015;

36. Larsen JS, Hansen AJT and Santos IF. Experimental and theoretical analysis of a rigid rotor supported by air foil bearings. Mechanics and Industry 2015; 16(1): 106 (1-13).

37. Simmons GF, Cerda Varela AJ, Santos IF et al. Dynamic characteristics of polymer faced tilting pad journal bearings. Tribology International 2014; 74: 20-27.

38. Nelson H and McVaugh J. The Dynamics of Rotor-Bearing Systems Using Finite Element. J Eng Ind 1976; 98: 593-600.

39. Schweitzer G, Maslen EH and Keogh P. Magnetic Bearings. Berlin, Heidelberg: Springer Berlin Heidelberg, 2009. ISBN 978-3-642-00496-4.

40. Guide to the expression of uncertainty in measurement (GUM:1995). ISO, Geneva, Switzerland, 2008. p. 120.

41. Rodriguez LE and Childs DW. Frequency Dependency of Measured and Predicted Rotordynamic Coefficients for a 
Load-on-Pad Flexible-Pivot Tilting-Pad Bearing. Journal of Tribology 2006; 128(2): 388.

\section{Appendix A: Effect of Control Law on Bearing Force Coefficients}

The matrix $[\mathbf{W}]$ defines the relationship between the control signals $\{\mathbf{u}\}$ and active fluid film forces $\{\mathbf{f}\}$, taking into account the dynamics of amplifiers, servovalves and pipelines. Normally, the matrix $[\mathbf{W}]$ is frequency dependent. Nevertheless, using short pipelines, high response servovalves and high values of pressurization such a frequency dependency can be neglected in the frequency range studied. Therefore the matrix $[\mathbf{W}]$ can be considered constant and defined by $W(k N / V)$ and $r$ as:

$$
[\mathbf{W}]=\left[\begin{array}{ll}
W_{x 1} & W_{x 2} \\
W_{y 1} & W_{y 4}
\end{array}\right]=\left[\begin{array}{cc}
W & W \\
-r W & W
\end{array}\right]
$$

In order to determine the effect of the control law on the bearing dynamic properties, the DOFs corresponding to lateral displacement at the ALB node (point T) are isolated in the equation of motion of Equation (1). By applying complex algebra, sorting out the DOFs of interest and considering only the active fluid film forces exerted, the steady-state system response can be expressed as:

$$
\left(-\omega^{2}\left[\begin{array}{ll}
\mathbf{M}_{\mathbf{T T}} & \mathbf{M}_{\mathbf{T O}} \\
\mathbf{M}_{\mathbf{O T}} & \mathbf{M}_{\mathbf{O O}}
\end{array}\right]+\left[\begin{array}{ll}
\mathbf{Z}_{\mathbf{T T}} & \mathbf{Z}_{\mathbf{T O}} \\
\mathbf{Z}_{\mathbf{O T}} & \mathbf{Z}_{\mathbf{O O}}
\end{array}\right]\right)\left\{\begin{array}{l}
\mathbf{q}_{\mathbf{T}} \\
\mathbf{q O}_{\mathbf{O}}
\end{array}\right\}=\left\{\begin{array}{c}
\mathbf{f}_{\mathbf{T}} \\
\mathbf{0}
\end{array}\right\}
$$

where the system dynamic stiffness $[\mathbf{Z}]=\left([\mathbf{K}]+\left[\mathbf{K}_{b}\right]\right)+$ $i \omega\left(\left[\mathbf{D}_{b}\right]-\Omega[\mathbf{G}]\right)$ has been introduced. The subscript $\mathbf{T}$ stands for the 2 DOFs related to the lateral displacement at the ALB node and $\mathbf{O}$ for the rest of the N-2 DOFs in the model. Unfolding the right hand side of Equation (9) to determine the expression of the active fluid film forces in terms of the gain matrix $[\mathbf{W}]$ and control signals $\{\mathbf{u}\}$, we obtain:

$$
\begin{aligned}
\left\{\begin{array}{c}
\mathbf{f}_{\mathbf{T}} \\
\mathbf{0}
\end{array}\right\}_{N x 1} & =\left[\begin{array}{c}
\mathbf{W} \\
\mathbf{0}
\end{array}\right]_{N x 2}\{\mathbf{u}\}_{2 x 1} \\
& =\left[\begin{array}{c}
\mathbf{W} \\
\mathbf{0}
\end{array}\right]_{N x 2}[\mathbf{C}]_{2 x 2}[\mathbf{0} \cdots \mathbf{I} \cdots \mathbf{0}]_{2 x N}\left\{\begin{array}{l}
\mathbf{q}_{\mathbf{T}} \\
\mathbf{q}
\end{array}\right\}_{N x 1}
\end{aligned}
$$

where $[\mathbf{C}]=\left[\mathbf{K}_{\mathbf{p}}\right]+i \omega\left[\mathbf{K}_{\mathbf{d}}\right]$ is the transfer function of the controller defined by the proportional $\left[\mathbf{K}_{\mathbf{p}}\right]$ and derivative $\left[\mathbf{K}_{\mathbf{d}}\right]$ gain matrices. $[\mathbf{I}]$ stands for the $2 \times 2$ identity matrix. The placement of the identity matrix within the matrix of dimension $2 \times N$ filled with zeroes [0] depends on the DOFs measured and fed back to the controller, i.e. the lateral movements at point (P). Equation (10) and Equation (9) can be rearranged as:

$$
\begin{aligned}
& \left(-\omega^{2}\left[\begin{array}{ll}
\mathbf{M}_{\mathbf{T T}} & \mathbf{M}_{\mathbf{T O}} \\
\mathbf{M}_{\mathbf{O T}} & \mathbf{M}_{\text {OO }}
\end{array}\right]+\left[\begin{array}{ll}
\mathbf{Z}_{\mathbf{T T}} & \mathbf{Z}_{\mathbf{T O}} \\
\mathbf{Z}_{\mathbf{O T}} & \mathbf{Z}_{\mathbf{O O}}
\end{array}\right]\right. \\
& \left.+\left[\begin{array}{l}
\mathbf{0} \cdots[\mathbf{W}][\mathbf{C}] \cdots \mathbf{0} \\
\mathbf{0} \cdots \cdot \mathbf{0} \cdots \cdots
\end{array}\right]\right)\left\{\begin{array}{l}
\mathbf{q}_{\mathbf{T}} \\
\mathbf{q}_{\mathbf{O}}
\end{array}\right\}=\left\{\begin{array}{l}
\mathbf{0} \\
\mathbf{0}
\end{array}\right\}
\end{aligned}
$$

Equation (11) shows that the variation in the system dynamic stiffness is $[\boldsymbol{\Delta} \mathbf{Z}]=[\mathbf{W}][\mathbf{C}]$. Depending on the DOFs fed back to the controller, $[\mathbf{Z}]$ is differently affected by the control law. If the lateral displacements of the journal at point $\mathrm{T}$ are fed back to the controller, then the change in $[\mathbf{Z}]$ will be influenced solely by the journal movements, i.e. $\left[\hat{\mathbf{Z}}_{\mathbf{T T}}\right]=\left[\mathbf{Z}_{\mathbf{T T}}\right]+[\boldsymbol{\Delta} \mathbf{Z}]$. If other DOFs are used for building up the control law, for instance the shaft extremity (point $\mathrm{P}$ ), then nodes $\mathrm{T}$ and $\mathrm{O}$ are coupled via the controller and the lateral movements of node $\mathrm{P}$ will influence $[\mathbf{Z}]$ and thereby the bearing force coefficients, i.e. $\left[\hat{\mathbf{Z}}_{\mathbf{T O}}\right]=\left[\mathbf{Z}_{\mathbf{T O}}\right]+[\boldsymbol{\Delta} \mathbf{Z}]$. By applying a dynamic condensation to keep only the ALB DOFs, the reduced stiffness and damping matrices of the ALB can be defined as follows:

$$
\begin{aligned}
{[\hat{\mathbf{K}}]=\Re\left(\mathbf{Z}_{\mathbf{T T}}+\right.} & \left(\omega^{2} \mathbf{M}_{\mathbf{T O}}-\hat{\mathbf{Z}}_{\mathbf{T O}}\right) \\
& \left.\left(\omega^{2} \mathbf{M}_{\mathbf{O O}}-\mathbf{Z}_{\mathbf{O O}}\right)^{-1}\left(\omega^{2} \mathbf{M}_{\mathbf{O T}}-\mathbf{Z}_{\mathbf{O T}}\right)\right)
\end{aligned}
$$

$$
\begin{aligned}
\omega[\hat{\mathbf{D}}]=\Im\left(\mathbf{Z}_{\mathbf{T T}}+\right. & \left(\omega^{2} \mathbf{M}_{\mathbf{T O}}-\hat{\mathbf{Z}}_{\mathbf{T O}}\right) \\
& \left.\left(\omega^{2} \mathbf{M}_{\mathbf{O O}}-\mathbf{Z}_{\mathbf{O O}}\right)^{-1}\left(\omega^{2} \mathbf{M}_{\mathbf{O T}}-\mathbf{Z}_{\mathbf{O T}}\right)\right)
\end{aligned}
$$

- Control Law \#1 - the elements of the matrix $[\Delta \mathbf{Z}]$ are determined as follows:

$[\Delta \mathbf{Z}]_{\# 1}=[\mathbf{W}][\mathbf{C}]=$

$\left[\begin{array}{cc}W & W \\ -r W & W\end{array}\right]\left(\left[\begin{array}{cc}k_{p} & k_{p} \\ -k_{p} & k_{p}\end{array}\right]+i \omega\left[\begin{array}{cc}k_{d} & k_{d} \\ -k_{d} & k_{d}\end{array}\right]\right)$

$[\Delta \mathbf{Z}]_{\# 1}=$

$W k_{p}\left[\begin{array}{cc}0 & 2 \\ -(1+r) & (1-r)\end{array}\right]+i \omega W k_{d}\left[\begin{array}{cc}0 & 2 \\ -(1+r) & (1-r)\end{array}\right]$

Equation (13b) shows that the control law \#1 significantly influences the cross coupling coefficients, whereas the direct coefficient in $y$ direction is less affected. The direct coefficient in $x$ direction is kept unaltered by the controller.

- Control Law \#2 - the elements of the matrix $[\Delta \mathbf{Z}]$ are determined as follows:

$$
\begin{aligned}
& {[\Delta \mathbf{Z}]_{\# 2}=[\mathbf{W}][\mathbf{C}]=\left[\begin{array}{cc}
W & W \\
-r W & W
\end{array}\right]\left[\begin{array}{cc}
k_{p_{1}} & k_{p_{2}} \\
r k_{p_{1}} & -k_{p_{2}}
\end{array}\right]} \\
& {[\Delta \mathbf{Z}]_{\# 2}=\left[\begin{array}{cc}
W k_{p_{1}}(1+r) & 0 \\
0 & -W k_{p_{2}}(1+r)
\end{array}\right]}
\end{aligned}
$$

It becomes evident that by using the control law \#2 the direct force coefficients are the only ones affected and the cross coupling coefficients remain unchanged.

\section{Appendix B: Bearing Force Coefficients - Influence of Lubricant Feeding and Loading}

Figures 10 and 11 report the changes in the bearing stiffness coefficients due to lubricant supply pressure (mist lubrication between pads) and loading condition under the passive lubrication regime. Figure 10 clarifies that an increase in the lubricant supply pressure does not significantly affect the stiffness coefficients, eliminating the hypothesis of starving 


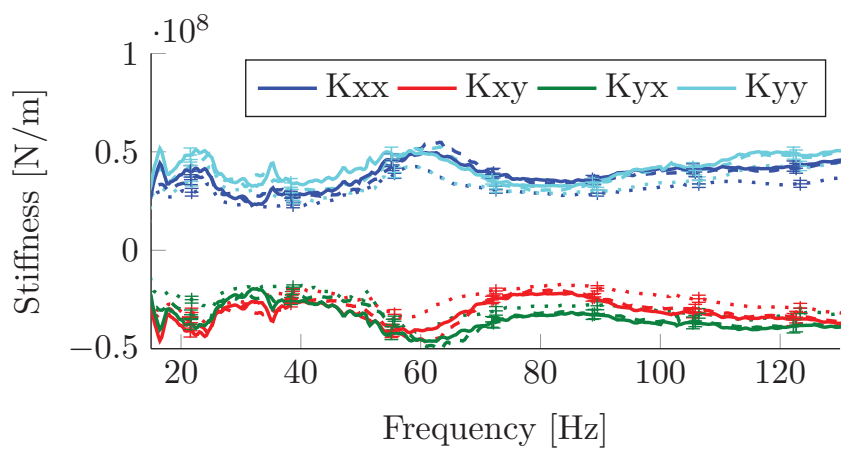

Figure 10. Identified dynamic stiffness for the ALB under passive lubrication regime. Different feeding pressures. Doted lines (..): 0.50 bar. Dashed lines (--): 1.50 bar. Solid lines (-): 2.40 bar.

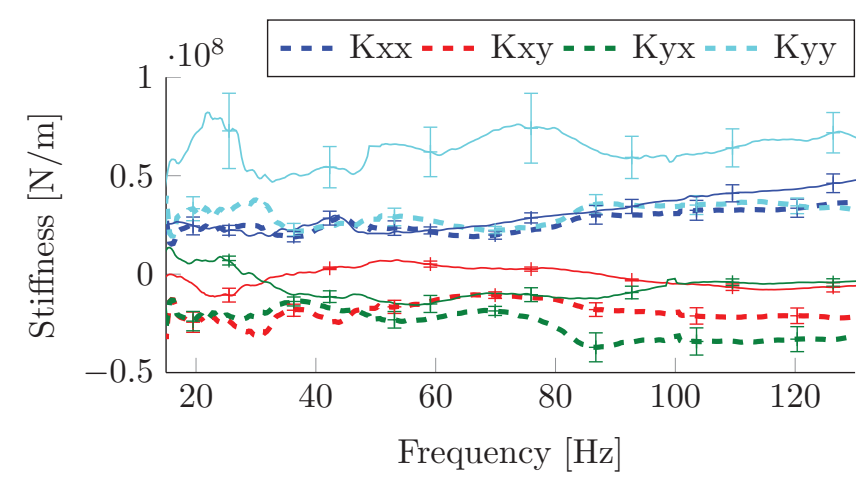

Figure 11. Identified dynamic stiffness for the ALB under passive lubrication regime. Different loading conditions. Solid lines (-): $900 \mathrm{~N}$ downward loaded. Dashed lines (--): Light-load condition.

lubrication conditions contributing to a high level of cross coupling coefficients.

Figure 11 shows the bearing stiffness coefficients under two different load conditions, i.e., a) lightly-loaded and b) downward loaded via AMB. It is evident that the loading significantly affects the order of the cross-coupling coefficients compared to the direct ones.

\section{Notation}

$A$
$[\mathbf{C}]$
$\left[\mathbf{D}_{b}(i \omega)\right]$
$\mathrm{D}_{i j}$
$\mathrm{~d}_{i j}$
$\{\mathbf{f}\}$
$[\mathbf{F R F}(i \omega)]$
$\left[\mathbf{F R F} F^{*}(i \omega)\right]$
$[\mathbf{G}]$
$\left[\mathbf{H}_{b}(i \omega)\right]$
$i$
$[\mathbf{K}]$
$\left[\mathbf{K}_{b}(i \omega)\right]$
$\mathrm{K}_{i j}$
$\mathrm{k}_{i j}$
$\left[\mathbf{K}_{p}\right]$
$\left[\mathbf{K}_{d}\right]$
$k_{d}$
$k_{p}, k_{p_{1,2}}$
$\mathrm{l}_{i j}$
$[\mathbf{M}]$
$\mathrm{M}^{S}$
$\mathrm{M}^{R}$
$\mathrm{M}^{E}$
$P_{\text {sup }}$

$\{\mathbf{q}\},\{\dot{\mathbf{q}}\},\{\ddot{\mathbf{q}}\}$

$q_{h_{1,2}}(t)$

$q_{l}(t)$

$q_{r}(t)$

$r$

$\mathrm{r}^{S}, \mathrm{r}^{R}, \mathrm{r}^{E}$

$\left[\mathbf{S}_{j}\right]$

$u_{1,2}$

$[\mathbf{W}]$

$W, W_{i j}$

$x_{\mathrm{P}}$

$\dot{x}_{\mathrm{P}}$

$y_{\mathrm{P}}$

$\dot{y}_{\mathrm{P}}$

$[\mathbf{Z}],\left[\mathbf{Z}_{0}\right]$

$[\boldsymbol{\Delta} \mathbf{Z}]$

$\omega$

$\Omega$
Mean value of radius (m)

Controller transfer function matrix

Bearing damping matrix

Identified bearing damping

Theoretical bearing damping

Generalized external force vector

Theoretical frequency response functions

Measured frequency response functions

System gyroscopic matrix

Bearing complex impedance function

Complex unity, $\sqrt{-1}$

System stiffness matrix

Bearing stiffness matrix

Identified bearing stiffness

Theoretical bearing stiffness

Proportional gain matrix

Derivative gain matrix

Derivative gain $(V s / m)$

Proportional gains $(V / m)$

Distance between points " $i$ " and " $j$ " $(m)$

System inertia matrix

Shaft mass $(\mathrm{kg})$

Active magnetic bearing rotor mass $(\mathrm{kg})$

Excitation bearing mass $(\mathrm{kg})$

Oil supply pressure

of the radial injection unit (bar)

Generalized displacement, velocity and acceleration coordinate vectors

High pressure oil flow $1,2\left(\mathrm{~m}^{3} / \mathrm{s}\right)$

Low pressure oil flow $\left(\mathrm{m}^{3} / \mathrm{s}\right)$

Return oil flow $\left(\mathrm{m}^{3} / \mathrm{s}\right)$

Constant of the servovalve gain " $W_{x 4}$ "

radius of shaft, magnetic rotor and excitation bearing $(m)$

selector matrix related to the " $j$ " DOF

Control signal of servovalve $1,2(V)$

Servovalve gain matrix

Servovalve gain $(N / V)$

$i=x, y, j=1,2$

: Journal horizontal displacement at point $\mathrm{P}(m)$

Journal horizontal velocity at point $\mathrm{P}(\mathrm{m} / \mathrm{s})$

Journal vertical displacement at point $\mathrm{P}(m)$

Journal vertical velocity at point $\mathrm{P}(\mathrm{m} / \mathrm{s})$

Rotor and rotor-bearing system dynamic stiffness matrices

System dynamic stiffness variation

Excitation frequency $(\mathrm{Hz})$

: Shaft angular velocity $(\mathrm{rpm})$ 